\title{
Un "golpe de estado" y sus consecuencias: el gobierno del infante don Enrique en Castilla (julio-diciembre de 1420)
}

\author{
A "Coup d'Etat" and its Consequences: The government of \\ Infante D. Enrique in Castile (July-December 1420)
}

\author{
Santiago GonZÁLEZ SÁnCHEZ \\ Universidad Complutense. Madrid \\ santitrifo@yahoo.es
}

\section{RESUMEN}

Estudio sobre las circunstancias que dieron lugar al "golpe de Estado" de Tordesillas en julio de 1420, analizando las fases y ejecución del plan diseñado, las razones que se dieron para acabar con el sistema de gobierno y los apoyos legales, políticos y morales que los sublevados emplearon para legitimar su acción. Los nuevos gobernantes, una reducida facción de la nobleza, por incapacidad, falta de tiempo y otras razones, no desarrollaron una acción de gobierno, y se limitaron a satisfacer sus aspiraciones de medro personal. El final de este breve periodo vino determinado por tres factores principales: las discordias dentro del propio grupo gobernante, la oposición armada encabezada por el infante don Juan y la voluntad del rey por liberarse, en quien influyó don Álvaro de Luna, principal beneficiario del fracaso del "golpe de estado".

Palabras clave: Castilla, Juan II, Infante don Enrique, Infante don Juan, Álvaro de Luna, Tordesillas, Ávila, Talavera, Montalbán, Siglo Xv.

\begin{abstract}
A study of the circumstances that caused the July 1420 coup d'état in Tordesillas, giving details on the stages and the fulfilment of the designed plan, the reasons given to overthrow the government, and the legal, political and moral support that the insurgents used to legitimate their actions. The new rulers, a reduced faction of the nobility, did not develop a plan of government due to their inability, lack of time and other reasons, yet satisfied their ambitions for personal improvement. The end of this short period of time was determined by three main factors: discord inside the ruling group, armed opposition led by the Infante D. Juan, and the king's will to be set free, which favored D. Álvaro de Luna, the great beneficiary.
\end{abstract}

Key words: Castile, Juan II, Infante D. Enrique, Infante D. Juan, Álvaro de Luna, Tordesillas, Ávila, Talavera, Montalbán, Fifteenth century.

Sumario: Introducción. 1. El Golpe. 2. El gobierno. 3. La caída. 3.1. Las diferencias entre los sublevados. 3.2. La oposición armada. 3.3. Los deseos del rey por liberarse. 4. Las consecuencias. Conclusiones. 


\section{INTRODUCCIÓN}

La evolución política de Castilla entre finales de 1406, acceso de Juan II al trono por la muerte de su padre Enrique III e inicio de la regencia conjunta entre la reina doña Catalina de Lancáster y el infante don Fernando de Castilla, y las mismas fechas de 1420 puede dividirse grosso modo en dos etapas atendiendo a la estabilidad gubernamental. Una primera, que comprendió el periodo de la regencia de Juan II y que esencialmente abarcó hasta la muerte del rey Fernando I de Aragón en 1416, con momentos de mayor o menor influencia de uno de los dos corregentes, pero en general con predominio del infante-rey don Fernando, y una segunda parte, que se extendió desde entonces hasta finales de 1420, en la que se ensayan diferentes sistemas de gobierno y todos fracasan propiciando la consiguiente inestabilidad. En efecto, tras la muerte de don Fernando, doña Catalina se convirtió en regente única, pero se vio condicionada por el triunvirato formado por Diego López de Stúñiga, justicia mayor, por Juan Fernández de Velasco, camarero mayor y por Sancho de Rojas, arzobispo de Toledo, de lo que son buena muestra la expulsión de los parciales que la reina tenía en la corte y hacerse con la tutela del monarca. Este sistema de gobierno duró aproximadamente dos años y sus consecuencias en el corto y medio plazo pueden resumirse en un mayor control del monarca y de su madre, en la ruptura de la «unidad» entre los grandes, en la acentuación de los bandos en la corte y en el protagonismo del arzobispo de Toledo. La muerte de los dos primeros y más tarde la de la reina, en junio de 1418, dio paso a un gobierno de tipo personalista dirigido por el arzobispo de Toledo que mantuvo su influencia hasta las Cortes de Madrid de 1419. A partir de entonces se ensayó un gobierno integrado por cinco grandes, que tuvo como fundamento el de la mayoría y que solo duró hasta el verano de ese mismo año. El infante don Enrique, maestre de Santiago, fue el principal beneficiario del gobierno que se formó, en detrimento de su hermano el infante don Juan, pues el primero a través de sus fieles Ruy López Dávalos, Pedro Manrique y Gutierre de Toledo pasaba a controlar, en gran medida, el gobierno del reino. Esto dio origen a rivalidades y desavenencias entre los dos infantes que amenazaban con derribar la estructura política diseñada por su padre y que provocaron la intervención de su madre, la reina viuda, doña Leonor. La reconciliación entre los infantes y las diferencias existentes entre los grandes dieron paso a una nueva modificación en la estructura de gobierno que pretendía una mayor integración nobiliaria, pues lo formaban un grupo más numeroso de nobles que irían rotando por cuatrimestres y que se mantuvo hasta el «golpe» del infante don Enrique el 14 de julio de 1420 .

En efecto, los planes diseñados por don Fernando para sus hijos tenían como eje principal a Castilla, base de su poder político y económico. Los infantes Enrique y Sancho estarían al frente de las órdenes militares de Santiago y de Alcántara, respectivamente, correspondiéndoles principalmente parte de la herencia de su madre.

Por su parte, el infante don Juan fue investido con el título de conde de Peñafiel, en la ceremonia de coronación de don Fernando en Zaragoza, y ostentaba el señorío de Lara, lo que hacía de él la cabeza de la nobleza castellana, no únicamente de manera formal, sino efectiva, pues también se contaban entre sus posesiones las que le donó su padre y parte de las que su madre tenía en la Rioja. Tras el fallido intento por 
casarle con la reina de Nápoles y el deseo siciliano de hacerlo su rey, don Fernando pensó en convertir a su hijo en regente de las provincias que él administraba, entre otras razones para que acabara con la situación levantisca de parte de la nobleza del reino, principalmente en Andalucía y prosiguiese su labor de conquista frente al reino de Granada, don Juan debía de quedar al frente y como salvaguarda de los intereses familiares en Castilla. Sin embargo, ese plan no se llevó a efecto entre otras razones por la muerte del rey don Fernando y por mediar órdenes en contrario del rey Alfonso, su hermano

Los infantes Enrique y Sancho tuvieron a Castilla como centro de sus intereses, ya en vida de su padre, no así el infante don Juan. Sin embargo, ni don Enrique ni don Juan desempeñaron un papel político importante hasta después del matrimonio de su hermana María con Juan II de Castilla, a finales de 1418.

\section{EL GOLPE}

Las circunstancias propicias para acabar con el sistema se produjeron con la marcha del infante don Juan a Navarra. La elección del reino pirenaico para celebrar su boda con Blanca de Navarra fue objeto de controversia en el Consejo Real, al proponerlo el infante don Enrique, que hizo que, al final, su hermano acabara aceptando ${ }^{1}$ y facilitando sus aspiraciones políticas.

Ignoro con exactitud la fecha de salida del infante don Juan de Castilla, aunque consta que los días 4 y 5 del mes de julio estaba en Tudela y Caparroso, camino de Pamplona ${ }^{2}$. Si además se tiene en cuenta la fecha del matrimonio, que varía aproximadamente una semana dependiendo de los autores, y se considera que su regreso a Castilla se inició poco después de su boda, como consecuencia de los sucesos de Tordesillas, se ve claramente que apenas si consumió la mitad de los cuarenta días que se le concedieron de permiso ${ }^{3}$.

Otras circunstancias que facilitaron el levantamiento del infante don Enrique fueron que el rey tenía en esos momentos poca gente de armas ${ }^{4}$; la ausencia del arzo-

${ }^{1}$ L. SuÁrez Fernández, Los Trastámaras de Castilla y Aragón en el siglo xV (1410-1474), en Historia de España de Menéndez Pidal, Tomo xv, Madrid, 1970, p. 74, para la primera afirmación. J. DE MORET Y FCO. DE Alesón, Annales del Reyno de Navarra, Tomo iv, Bilbao, 1969, p. 353 (Reproducción facsímil).

2 J. R. CAstro, Archivo General de Navarra. Catálogo de la Sección de Comptos. Documentos, vol. xxxII, Pamplona, 1963, n. ${ }^{\circ}$ 294, pp. 158-159.

${ }^{3}$ Sobre la fecha de celebración de la boda hay discrepancia por cuanto F. PÉrez DE GuzMán, Crónica del serenísimo príncipe don Juan, segundo rey deste nombre en Castilla y León, escrita por el noble y muy prudente caballero Fernán Pérez de Guzmán, Señor de Batres, del su Consejo, B.A.E., Colección ordenada por don Cayetano Rosell, vol. LXVIII, t. II, Madrid, 1953. p. 382; J. DE Moret y FCO. DE Alesón, Annales del Reyno..., p. 353, y P. A. Porras Arboledas, Juan II 1406-1454, Palencia, 1995, pp. 94-95, aunque yerran en el mes, ponen junio, señalan que fue el día 18. L. SuÁrez FernÁNDEz, Los Trastámaras ..., p. 74, y J. DEL Burgo, Historia general de Navarra. Desde los origenes hasta nuestros días, Tomo II, Madrid, 1992, p. 68, indican que fue el día 10 de julio.

${ }^{4}$ G. Chacón, Crónica de don Álvaro de Luna. Condestable de Castilla y Maestre de Santiago, Edición y estudio por Juan de Mata Carriazo y Arroquia, Madrid, 1940, p. 36. Sin embargo, en la guarda del rey había cien lanzas en esos momentos, según señala Á. GARCía DE SANTA MARÍA, Crónica de Don Juan II de Castilla, 
bispo de Toledo de la corte, ya que «... estaba flaco en Valladolid» ${ }^{5}$; y la finalización de las Cortes de Valladolid, con la marcha de la mayoría de los procuradores de las ciudades $^{6}$, sin olvidar los infiltrados que tenía el infante don Enrique en palacio ${ }^{7}$.

En el «secuestro», «golpe», «golpe de mano», «atraco», «insulto» o «movimiento» de Tordesillas concurren la premeditación, nocturnidad y alevosía. Aquí nos interesan la primera y la tercera. Según alguna fuente, el grupo favorable al infante don Enrique elaboró un plan desde la ruptura de la rotación cuatrimestral ${ }^{8}$, aunque los preparativos para llevarlo a cabo es posible que se hiciesen pocas horas antes ${ }^{9}$. En la materialización de ese plan se contienen la sorpresa, la cautela, el empleo de las armas y los infiltrados ${ }^{10}$. El proyecto no consistía únicamente en alejar de la corte al infante don

por el marqués de la Fuensanta del Valle D. José Sáncho Rayón y D. Francisco Zabalbúru, CoDoIn, vol. xcIX, Madrid, 1891, p. 91.

5 Á. García de Santa María, Le parti inedite della: "Crónica de Juan II" di Álvar García de Santa María, Edizione critica, introduzione e note a cura di Donatella Ferro, Venezia, 1972, p. 223. Estas palabras del cronista debemos tenerlas en consideración; sin embargo, si se comparan con la actividad desarrollada por el prelado al conocer lo ocurrido en Tordesillas o con su trayectoria anterior, deben tomarse con cierta cautela. Á. García de SANTA María, Crónica ..., (1891), p. 96, da cuenta de la reacción inmediata del arzobispo de Toledo al golpe de Tordesillas. En adelante omito la referencia cronológica de esta crónica, pues en todos los casos es la editada en 1891.

${ }^{6}$ Cortes de los antiguos reinos de León y de Castilla, vol. III, Madrid, 1866, pp. 30-36.

${ }^{7}$ En concreto de Sancho de Hervás, que estaba en la cámara de los paños, y del obispo de Segovia, Juan Vázquez de Cepeda o de Tordesillas, de los cuales «... eran avisados de todo lo que en el palacio se hacía». F. Pérez de Guzmán, Crónica ..., p. 381. Ó. Villarroel González, "Servir al rey en las ligas nobiliarias: los eclesiásticos en las confederaciones políticas", Anuario de Estudios Medievales, 36/2 (2006), p. 759, destaca el papel de este prelado en la preparación del golpe.

${ }^{8}$ L. De Barrientos, Refundición de la Crónica del Halconero, Edición de Juan de Mata Carriazo y Arroquia, Madrid, 1946, p. 33.

9 V. Á. Álvarez Palenzuela, "Enrique, Infante de Aragón, Maestre de Santiago", Medievalismo. Boletín de la Sociedad Española de Estudios Medievales, 12 (2002), p. 47.

${ }^{10}$ Tomarían parte en esta acción unos trescientos hombres de armas según FCO. CARO DE TorREs, Historia de las órdenes Militares de Santiago, Calatrava y Alcántara desde su fundación hasta el Rey Don Filipe Segundo Administrdor perpetuo dellas, Madrid, 1629, fol. 38v, que lo debe recoger de una edición anterior de la crónica de F. Pérez de GuzMÁn, Crónica ..., p. 381. Por lo tanto, hay que ser cauto al admitir las afirmaciones de Juan II, aún bajo la tutela de su primo que, dirigiéndose a Murcia el 11 de agosto de 1420, desde Ávila, y en referencia a Tordesillas, señala que «... no se había producido violencia alguna», como tomo de J. ABELLÁN Pérez (ed), Documentos de Juan II, CODOM, vol. xvi, Murcia-Cádiz, 1984, n. ${ }^{\circ} 37$, pp. 81-85. En el mismo sentido, por tratarse de la defensa del condestable se afirma que «... llegaron a la vuestra señoría estando en los vuestros palacios de la dicha villa de Tordesillas en los quales entraron los suso dichos con mucho moderamiento sin jente de armas salbo algunos dellos que traiyan sus espadas sinplemente... sin ynsulto alguno e sin otro escándalo». B.N., Col. Burriel, Mss. 13236 y R.A.H., Salazar y Castro, N-5, fols. 1r-43r, este último publicado por Y. Guerrero Navarrete, Proceso y sentencia contra Ruy López Dávalos, Condestable de Castilla, Jaén, 1982, pp. 50-121. Quizá haya que matizarlo al conocer por varias fuentes que el infante mandó a sus hombres que llevasen cotas brazaletes y que algunos fueron donde dormían «... desnudas sus espadas», como señala M. Jimena JuRADo, Historia o anales del mvnicipio Albense Vrgavonense o villa de Arjona, Arjona, 1996, p. 403 (Facsímil de la de Jaén de 1665). El empleo de la violencia es un componente esencial de la cultura medieval, en concreto por parte de la nobleza, no solo en la guerra, sino también en las relaciones interpersonales, por razones como la inexistencia de los mecanismos que la rigen, por parte de una autoridad centralizada, o por su justificación por los sectores de la élite social. V. M. Gibello Bravo, La imagen de la nobleza castellana en la Baja Edad Media, Cáceres, 1999, p. 157. CL. GAUVARD, "Le coup d'État, de l'émotion à la sujétion", Coups d'État à la fin du Moyen Âge? Aux fondements du pouvoir politique en Europe occidentale, François Foronda, Jean-Philippe Genet y José Manuel Nieto Soria (dirs.), Madrid, 2005, p. 609, señala 
Juan, apoderarse del monarca ${ }^{11} \mathrm{y}$ hacerse con las riendas del gobierno ${ }^{12}$, también tenía una vertiente que, si no fuera por su importancia política, cabría calificar como de índole privada: esta era el secuestro de la infanta doña Catalina, en quien el infante don Enrique había puesto sus esperanzas de medro ${ }^{13}$. Tal como nos ha llegado la narración de los hechos de lo que ocurrió en el palacio ${ }^{14}$, el plan se ejecutó en varias fases, cada una de ellas de forma muy rápida: la primera comprendería la entrada forzada en el recinto ${ }^{15}$; la segunda, el arresto del hombre fuerte del momento, Juan Hurtado de Mendoza, por parte de Pero Niño ${ }^{16}$, y la detención de su sobrino Pedro González

la necesidad de que se complementen el poder civil y el militar para que el golpe tenga éxito. Los hechos de Tordesillas se ajustan prácticamente a la perfección a los caracteres de un golpe de Estado: secretismo en su preparación, rapidez en su ejecución y carácter violento, que señala E. GoNZÁLEZ CALLEJA, Los golpes de Estado, Madrid, 2003, pp. 9-10, esencialmente.

${ }^{11}$ J. M. Nieto Soria, "Más que palabras. Los instrumentos de la lucha política en la Castilla bajomedieval”, XIV Semana de Estudios Medievales (Nájera, del 4 al 8 de agosto de 2003). Conflictos sociales, politicos e intelectuales en la España de los siglos XIV y XV. José Ignacio de la Iglesia Duarte (coordinador), Logroño, 2004, p. 187, señala el valor político del secuestro del rey y las posibilidades de ser decisivo. F. Foronda, "S'emparer du roi. Un rituel d'intégration politique dans la Castille trastamare", Coups d'État à la fin du Moyen Âge?..., Madrid, 2005, p. 213, destaca que para la aristocracia castellana de los siglos XIV y xv apoderarse del rey era como un hábito. M. Á. LADERo QuesADA, “¿Golpes de Estado a fines de la Edad Media? Fundamentos del poder político en la Europa Occidental", Coups d'État à la fin du Moyen Âge?..., Madrid, 2005 , pp. 599 y 602, respectivamente, estima que existe una tendencia a reducir al monarca a un primus inter pares, y que se consideraba preferible hacerse con el control de su persona y sus poderes a deponerlo.

${ }^{12}$ E. González Calleja, Los golpes..., p. 16 y M. Á. Ladero Quesada, “¿Golpes de Estado...”, p. 602, coinciden cuando, cada uno desde su perspectiva de análisis, afirman que uno de los objetivos de los golpes de Estado es sustituir al anterior equipo gobernante por otro.

${ }^{13}$ Según M. ${ }^{\text {a }}$ C. Quintanilla Raso, "Facciones, clientelas y partidos en España en el tránsito de la Edad Media a la Modernidad", Poder, economía y clientelismo, Javier Alvarado coordinador, Madrid, 1997, p. 19, los móviles derivados de las ambiciones individuales tenían un gran peso en la constitución y actuación de los partidos políticos. Estas cuestiones serían las distintas partes que componían el plan de los sublevados, según L. SuÁrez Fernández, "Auge y caída de un hombre nuevo: el condestable Ruy López Dávalos", Boletín de la Real Academia de la Historia, CXCV/1 (1998), p. 76.

${ }^{14}$ J. M. Nieto Soria, "Más que palabras...", p. 198, considera al golpe de mano en el medio cortesano, incluido el apoderamiento del rey o de algunos de sus oficiales, como una de las fórmulas más rotundas de expresión de la lucha política. FCO. DE P. CAÑAS GÁLVEz, La burocracia regia durante el reinado de Juan II de Castilla: Estudio prosopográfico e itinerario, Tesis doctoral, Universidad Complutense, vol. I, Madrid, 2005 , p. LI, señala que crónicas y documentos permiten atisbar la posibilidad de que hubiese dos palacios en Tordesillas, el antiguo castillo y los palacios urbanos. Serían los palacios urbanos, construidos en tiempos de Enrique III, los que sirvieran de residencia regia, y, por lo tanto, en los que tuvieron lugar los hechos que aquí se tratan. La ubicación, dimensiones, fines, etc., de estos palacios los ha estudiado de forma concienzuda M. Á. ZaLAmA, Vida cotidiana y arte en el palacio de la reina doña Juana I en Tordesillas, Valladolid, $2003^{2}$, pp. 132-139, especialmente.

${ }^{15}$ G. Chacón, Crónica ..., p. 36.

${ }^{16}$ G. Díez de Games, El Victorial. Crónica de don Pero Niño Conde de Buelna, Edición y estudio Juan de Mata Carriazo, Madrid, 1940, pp. 322-323; F. Pérez de Guzmán, Crónica ..., p. 381. V. Á. Ál evarez PalenzUELA, "Enrique, Infante...", pp. 38-39 y 47, llama la atención sobre el servicio de Pero Niño al infante. Sin embargo, creeo que quizá la razón principal pueda encontrarse en la relación, sin duda afectiva pero también familiar, que le unía con el condestable Dávalos, ya que estaba casado con la cuñada de este último, doña Constanza Vélez de Guevara. También es importante recordar que tiempo atrás el futuro conde de Buelna y el maestre de Santiago aspiraron a casarse con doña Beatriz, hija del infante portugués don Juan. Sobre los amores de esta señora y Pero Niño tratan los poemas números 10, 32, 33 y 42 del Cancionero de Juan Alfonso de Baena, de los que trata R. Beltrán Llavador, "La presencia de Pero Niño, conde de Buelna, en el 
de Mendoza, señor de Almazán, por Pedro Fernández de Velasco ${ }^{17}$; y la tercera, la comparecencia ante el rey de los responsables del acto para justificarlo ${ }^{18}$.

Los principales comprometidos en la quiebra de la fidelidad ${ }^{19}$ y lealtad debidas al monarca $^{20}$ eran, además del infante don Enrique, Ruy López Dávalos, Pedro Manrique, su primo García Fernández Manrique, Pedro Fernández de Velasco, Pero Niño y Juan de Tordesillas, obispo de Segovia. Es significativo destacar, al menos, los casos del condestable y del adelantado de León, ausentes de la corte: el primero por estar

Cancionero de Baena", Juan Alfonso de Baena y su Cancionero. Actas del I Congreso Internacional sobre el Cancionero de Baena, Editores Jesús Luis Serrano Reyes y Juan Fernández Jiménez, Baena, 2001, pp. 3-14. Sobre el episodio del Victorial que narra los amores entre Pero Niño y doña Beatriz y su influencia en la trama de Cárcel de Amor de Diego de San Pedro véase M. PARDO, "Un épisode du Victorial: biographie et élaboration romanesque", Romania, LXXXv (1964), pp. 269-292.

${ }^{17}$ G. Díez de GAmEs, El Victorial..., p. 323, es el único autor que señala quién llevó a cabo esta acción. G. Chacón, Crónica ..., p. 36 y F. Pérez de Guzmán, Crónica ..., p. 381, solo indican que el señor de Almazán fue puesto en su poder. Para E. GonzÁlez Crespo, Elevación de un linaje noble castellano en la Baja Edad Media: Los Velasco, Madrid, 1981, pp. 296-297, las razones del alineamiento de Pedro Fernández de Velasco al lado del infante don Enrique se deberían a su inexperiencia y a la intromisión del infante don Juan en los asuntos de la Merindad de Castilla Vieja. Esta última explicación parece más factible, porque las encomiendas de la Merindad de Castilla Vieja no querían permanecer bajo la influencia de los Velasco. A ésta idea se adhiere M. ${ }^{a}$ J. García Vera, La nobleza castellana bajomedieval. Bases de su predominio y ejercicio de su poder en la formación político-social del siglo XV: el reinado de Enrique IV, Tesis doctoral inédita, Universidad Complutense, vol. I, Madrid, 1997, pp. 255-256. Creo que también pudieron pesar en su actuación estar apartado del sistema de rotación cuatrienal o la inclinación de alguno de sus familiares, como su primo Rodrigo de Velasco, obispo de Palencia, que también se cuenta entre los partidarios del infante don Enrique. F. PÉrez DE GuzMÁN, Crónica ..., p. 387. La filiación se puede ver en A.H.N., Sección Nobleza. Frías, caja. 363, n. ${ }^{\circ} 12$, de donde lo toman M.a T. Peña Marazuela y P. León Tello, Archivo de los Duques de Frías. I Casa de Velasco, Madrid, 1955, n. ${ }^{\circ} 526$, p. 81.

${ }^{18}$ G. Díez de Games, El Victorial..., p. 323; F. Pérez de Guzmán, Crónica ..., p. 381. J. de M. Carriazo y Arroquia (Ed.), "Los Anales de Garci Sánchez, jurado de Sevilla”, Anales de la Universidad Hispalense, XIV (1953), n. ${ }^{\circ} 93$, p. 26, se limita a decir que: «En este año tomaron al rey en Tordesillas el ynfante don Henrrique y los de su parte, y prendieron a Juan Hurtado, mayordomo mayor del rey, que lo traía, y a Mendoza señor de Almazán».

${ }^{19}$ Sobre este concepto es interesante el artículo de K. KIM, "Etre fidèle au roi: $\mathrm{XII}^{\mathrm{e}}$-XIV ${ }^{\mathrm{e}}$ siècle", Revue Hispanique, CCXCII/2 (1995), pp. 225-250. Este autor distingue entre fidelidad política y fidelidad vasallática, y cómo ésta última pierde, en cierta medida, su importancia jurídica, al tener que dejar un lugar a la fidelidad política. Por ello, el discurso jurídico europeo se reorganizará alrededor de este pactum político que une a todos los fieles en un cuerpo místico, del cual el rey es la cabeza.

${ }^{20}$ Según G. Chacón, Crónica..., p. 37, don Álvaro de Luna se dirigió a los sublevados con las siguientes palabras cuando entraron en las habitaciones del rey «... recuérdasevos de la grand deslealtad que acometéis». En las Partidas el desleal al monarca era considerado un traidor. Sobre este último concepto y desde un punto de vista jurídico era la ruptura del vínculo de fidelidad establecido entre personas determinadas o la violación grave de la lealtad debida. Por lo tanto, eran traidores aquellos que no observaban el juramento prestado, tal como expone A. Iglesia Ferreiros, Historia de la traición. La traición regia en León y Castilla, Santiago de Compostela, 1971, pp. 125, 178 y 251. En fechas más recientes, J. Matтoso, "La difusión de la mentalidad vasallática en el lenguaje cotidiano", Studia Historica. Historia Medieval, Iv (1986), p. 179, señala que el término traidor era el mayor de los insultos y que se convirtió en el concepto antitético postulado por el ideal de fidelidad, que valoraba especialmente los compromisos adquiridos en un juramento feudal. 
expulsado ${ }^{21}$ y el segundo porque se habría ido con él. Hasta esos momentos no hay constancia de que hubiesen regresado ${ }^{22}$.

Las razones aducidas para acabar con el sistema de gobierno y apoderarse de Juan II nos han llegado procedentes de la exposición de motivos que hicieron los sublevados ante el rey, de la que hizo don Gutierre Gómez de Toledo ante los procuradores reunidos en Avila ${ }^{23}$, pero sobre todo de la defensa del condestable Dávalos, de la propia reina y del monarca (en estos dos últimos casos todavía sometidos a presión $\mathrm{y}$, sin duda, vigilados, por estar bajo el control del infante don Enrique). Algunas de esas razones fueron: la alteración en la rotación cuatrimestral, la expulsión del condestable de la corte, la provisión de oficios a personas de la parcialidad de los que gobernaban y que no los merecían, las numerosas donaciones y gastos desordenados ${ }^{24}$, la imposición de nuevas contribuciones, las amenazas a la reina ${ }^{25}$, la incitación al rey para que usase el rigor y la severidad ${ }^{26}$, el tenerle engañado, las ligas y confederaciones que se hacían para perpetuarse en el poder, el alejamiento de los grandes y prelados de la corte, las ofensas al linaje del infante por los intentos de su

${ }^{21}$ Fernando de Aranda, defensor del condestable Dávalos en el proceso que se le incoó, señala que la razón para alejar al condestable de la corte fue que pretendía el matrimonio de su hijo Diego con una hija de Martín Fernández Portocarrero -sin duda, doña Elvira- unión que el rey había planeado para su criado don Álvaro de Luna. Y. Guerrero Navarrete, Proceso y sentencia..., pp. 32-33. Cabe preguntarse, por lo tanto, por el papel que desempeñó don Álvaro de Luna en esta cuestión pues se acabó casando con la citada señora.

${ }^{22}$ En los días previos al asalto de Tordesillas estarían, respectivamente, en Madrigal y en Amusco. Á. García de Santa María, Crónica ..., p. 85.

${ }^{23}$ Según J. M. Nieto Soria, "Rex inutilis y tiranía en el debate político de la Castilla bajomedieval", Coups d'État à la fin du Moyen Age?..., Madrid, 2005, pp. 82-83, a través del discurso del arcediano de Guadalajara se acepta « $\ldots$ desde la propia monarquía, la acción armada como forma de corregir la incompetencia regia, pero solo para corregirla, no para promover la deposición del rey».

${ }^{24}$ Las razones anteriores son las que expresó el defensor del condestable en el proceso que se le hizo, como publica Y. Guerrero NaVArRete, Proceso y sentencia ..., pp. 50-121. Sobre la avaricia y el interés nobiliario trata un capítulo de la obra de V. M. Gibello Bravo, La imagen ..., pp. 125-139.

${ }^{25}$ A la reina se le habría solicitado que hiciese ligas con los grandes del reino y en estrecha relación con ella el matrimonio del rey fue uno de los primeros objetivos de los que se habían levantado en Tordesillas. J. Abellán Pérez (ed), Documentos..., n. ${ }^{\circ}$ 37, pp. 81-85. Las amenazas a la reina de que si no hacía liga con ellos el rey no consumaría el matrimonio y ella pasaría a un monasterio, se pueden ver en la misiva que ella dirige al concejo de la ciudad de Murcia, con fecha 8 de agosto de 1420. A.M.M., Cartulario Real 1411-1429, fol. 106r, y en la carta que escribe Juan II al concejo de Carmona publicada por J. Hernández Díaz, A. SANCho Corbacho y Fco. Collantes de Terán, Colección diplomática de Carmona, Sevilla, 1941, pp. 48-50. Por su parte, G. Díez de Games, El Victorial..., p. 322, habla de la posibilidad de que Juan Hurtado de Mendoza y los de su opinión aconsejasen al rey que dejase a la infanta doña María por su hermana menor -doña Leonor- y así retrasar su matrimonio, para seguir manteniendo su influencia.

${ }^{26}$ J. L. Bermejo Cabrero, "Principios y apotegmas sobre la ley y el rey en la Baja Edad Media castellana", Hispania, xxxv/129 (1975), p. 46, recuerda que el amor y el miedo que el monarca debe infundir es una constante del pensamiento político. En Máximas, principios y símbolos políticos (Una aproximación histórica), Madrid, 1986, p. 32, señala que lo característico del tópico es que ambas expresiones se den unidas. Este mismo autor en "Amor y temor al rey. (Evolución histórica de un tópico político)", Revista de Estudios Políticos, 192 (1973), p. 109, señala que hay una gradación de obligaciones pues: «Es preciso conocer, amar, temer, honrar y guardar la persona del Rey, por este mismo orden. El amor precede, pues, al temor. Y aún más, el amor implica siempre temor». P. LóPez DE Ayala, Rimado de Palacio, en Biblioteca de Autores Españoles desde la formación del lenguaje hasta nuestros dias, vol. LVII, Madrid, 1966, p. 444, entre las nueve cosas que señala para conocer el poder del rey está «... ser muy presçiado e muy famoso ser/ El que non le amare que le pueda temer». 
hijo Enrique por casarse con la infanta doña Catalina y de que se le diese el señorío de Villena ${ }^{27}$, el ascendiente de don Abraham Bienveniste en el gobierno del reino, la codicia desordenada del grupo gobernante por hacerse con mercedes y juros de heredad ${ }^{28}$ o la necesidad de «... reparar los daños pasados e los que se esperaban por mengua de buena governacion ${ }^{29}$.

Con ser importantes estas denuncias (no hay por qué dudar de alguna de ellas) se necesitaba un apoyo legal que se encontró en las Partidas de Alfonso X, que señalaban que los que no evitasen el mal y el daño a su rey eran culpables de traición, que los vasallos tenían que guardar al rey de sí mismo y de los extraños y de que había que desaconsejarle hacer cosas por las que le pudiese venir mal y daño a él, a su linaje o al reino, de dos maneras: aconsejándole y haciéndole aborrecerlo ${ }^{30}$. Hay también un sustento moral a través de una concepción corporativa, pues los sublevados consideraban que el rey era la cabeza y el corazón del reino, al que no gobernaba porque dejaba el oficio y cuidado a otros de los miembros del cuerpo, al que juzgaban enfermo por falta de atención ${ }^{31}$. Por lo tanto, se recomienda al rey no fiarlo todo al cuidado de sus consejeros y devolver a su oficio su majestad y grandeza ${ }^{32}$. Se hacía, en su opinión, «... por servicio del Rey y bien universal de sus Reynos»» $»^{33}$.

\section{EL GOBIERNO}

Tomados los que tenían el poder y el centro desde el que se ejercía, los sublevados adoptaron las primeras medidas y se enfrentaron con las consecuencias de su acción. El primer día tomaron varias de importancia; con vistas a controlar la corte, expulsaron a todos los oficiales que habían estado con el rey en Tordesillas, de los que el más

27 B.N., Mss. 2507, fols. 142r-145v. Sobre la importancia del matrimonio del infante don Enrique con la infanta doña Catalina como uno de los objetivos que llevó al primero a levantarse contra el rey en Tordesillas, veáse R.A.H., Col. Salazar y Castro, C-12, fol. 79r-v.

${ }^{28}$ En un discurso que se pone en boca del infante don Enrique cuando se dirige a su primo el rey dice que estos consejeros eran «... lobos boraces que se apacientan y sustentan de la sangre de la república». B.N., Mss. 2507, fol. 147v. J. Hernández Díaz, A. Sancho Corbacho y Fco. Collantes de Terán, Colección diplomática ..., pp. 48-50. F. PÉrez de Guzmán, Crónica ..., p. 381, también alude a la importancia de don Abraham Bienveniste en el gobierno del reino.

${ }^{29}$ F. Pérez de Guzmán, Crónica ..., p. 387. J. M. Nieto Soria, “Más que palabras...”, p. 175, señala entre los elementos de la lucha política a la retórica reivindicativa en la que se dio el recurso a los memoriales de agravios.

${ }^{30}$ B.N., Mss. 2507, fol. 146r-v. Concretamente proceden de Las Siete Partidas, Madrid, 2004, II. Partd, tít. XIV, ley. XXV (Facsímil de la glosada por Gregorio López).

31 J. A. Maravall Casesnoves, "La idea de cuerpo místico en España antes de Erasmo", Estudios de historia del pensamiento español. Edad Media, Madrid, 20014 , pp. 171 y 172, señala que la idea de cuerpo significa unidad sobre la multiplicidad de partes. Unidad que se expresa en la pertenencia del poder y de su titular y de los sujetos a un mismo cuerpo, lo que confiere a esta imagen un valor político más próximo al interés actual. J. M. NiETo SoRIA, Fundamentos ideológicos del poder real en Castilla (siglos XIII-XVI), Madrid, 1988, pp. 227-228.

32 B.N., Mss. 2507, fol. 147r-v.

33 F. Pérez de Guzmán, Crónica ..., p. 381. 
importante era Fernando Alfonso de Robles ${ }^{34}$; se prestó especial atención en tener al monarca controlado, por lo que se pusieron nuevas guardas en su casa, otros que durmiesen en palacio de continuo y los que tenían que servirlo; y se decidió conceder a don Álvaro de Luna, hasta entonces doncel del rey, el puesto de consejero regio y otorgarle un importante salario ${ }^{35}$. Esta última medida intentaba atraerse la voluntad de Juan $\mathrm{II}^{36}$. También se hacía indispensable tranquilizar a la población de Tordesillas, y al reino en general, para lo cual se contó con la colaboración, posiblemente forzada ${ }^{37}$, del monarca, quien, a través de una serie de cartas, se dirigió al reino comunicando la nueva situación ${ }^{38}$.

El siguiente paso sería consolidarse en el poder, por lo que se adoptaron importantes disposiciones de carácter político como la ampliación del Consejo Real ${ }^{39}$. La decisión de reformarlo se tomó una semana después del hecho de Tordesillas y, siguiendo

${ }^{34}$ Sobre este personaje véanse F. Pérez de GuzMÁn, Generaciones, Semblanzas..., p. 711, y distintos estudios, como los que le han dedicado C. Espejo, "El leonés Fernand Alfonso de Robles, contador mayor de Juan II", Boletín de la Sociedad Castellana de Excursiones, III (1907-1908), pp. 170-175 y 177-184, y M. DiAgo Hernando, "El contador Fernán Alfonso de Robles. Nuevos datos para su biografía", Cuadernos de Historia de España, LXXv (1998-1999), pp. 117-133. También tratan su figura M. ${ }^{a}$ DEL C. CARLÉ, "Caminos del ascenso en la Castilla bajo medieval", Cuadernos de Historia de España, LXV-LXVI (1981), pp. 220-222 y 225-226, y C. Álvarez Álvarez, "Linajes nobiliarios y oligarquías urbanas en León”, La nobleza peninsular en la Edad Media. VI Congreso de Estudios Medievales, León, 1999, pp. 48-50.

${ }^{35}$ F. Pérez de Guzmán, Crónica ..., pp. 381 y 382, respectivamente; Á. García de Santa María, Crónica..., p. 94. M. Á. LADERO QueSADA, “¿Golpes de Estado...”, p. 603, señala que el control del rey consistía en el control de su cuerpo en la vida cotidiana, en el control de los símbolos de la realeza, de sus tesoros y de su cámara, de la gracia regia, del reparto de los oficios de la Casa y Corte y la obtención de señoríos jurisdiccionales, así como el control de los medios militares. Todo esto lo hicieron los sublevados.

${ }^{36}$ G. Chacón, Crónica ..., p. 37; F. Pérez de Guzmán, Crónica ..., p. 381. L. SuÁrez Fernández, Nobleza y Monarquía. Puntos de vista sobre la Historia castellana del siglo XV, Valladolid, 1959, p. 88, considera que el mantenimiento de don Álvaro de Luna en la corte fue un error, como evidentemente se demostraría poco después, sin olvidar que en aquel momento su continuidad representaba la estabilidad que deseaban los sublevados.

${ }^{37}$ La actitud de Juan II durante el primer día no podía ser de mayor descontento. Como muestra de ello valgan su negativa a responder a la petición de que enviase marchar a las cien lanzas que Juan Hurtado de Mendoza tenía en su guarda o su inapetencia durante la comida. Á. García de SANTA María, Crónica..., pp. 90-91 y 94.

${ }^{38}$ Por citar varios casos, hay constancia documentada de las que se enviaron en los meses de julio y de agosto. El 15 del primer mes a Burgos, como recogen J. A. Bonachía Hernando y J. A. Pardos Martínez, Catálogo documental del Archivo Municipal de Burgos: Sección Histórica (931-1515), vol. I, Burgos, 1983, n. ${ }^{\circ}$ 492, p. 224; a Cuenca, el 21, en Actas Municipales del Ayuntamiento de Cuenca. I. Años 1417, 1419 y 1420 , Edición, transcripción y notas Antonio Chacón Gómez-Monedero y Pedro Martínez Escribano, bajo la dirección de Miguel Jiménez Monteserín, Cuenca, 1994, p. 82; a Ciudad Rodrigo, el 22, en Á. BARrios GarCíA, J. M. ${ }^{a}$ Monsalvo Antón y G. Del Ser Qujuano, Documentación medieval del Archivo Municipal de Ciudad Rodrigo, Salamanca, 1988, n. ${ }^{\circ}$ 92, pp. 157-159. El 14 de agosto a Úbeda, en F. Ruano y Prieto, "El Condestable D. Ruy López Dávalos, primer Duque de Arjona", Revista de Archivos, Bibliotecas y Museos, $3^{\mathrm{a}}$ época, año VIII, XI julio-diciembre (1904), n. ${ }^{\circ}$ IV, p. 408 y en M. GonZÁlez JiMÉNEZ, "Documentos referentes a Andalucía en Nobleza de Andalucía de Gonzalo Argote de Molina", Historia. Instituciones. Documentos, 17 (1990), n. ${ }^{\circ}$ 86, p. 99. En el caso de Murcia no disponemos de la primera comunicación, sí de las de días posteriores, como publica J. Abellán Pérez (ed), Documentos..., n. ${ }^{\circ} 34$, pp. 78-79, además de varias referencias recogidas en las Actas Capitulares durante los meses de agosto, A.M.M., Actas Capitulares (1420 agosto 3), fol. 26v y (1420 agosto 17), fol. 29r, y de septiembre (1420 septiembre 12), fol. 35v.

${ }^{39}$ S. GonzÁlez SÁnchez, "El Consejo Real de Castilla durante la minoría de Juan II", En la España Medieval, 34 (2011), pp. 181-214, analiza la trayectoria, funcionamiento y estructura de esta institución, destacando 
las directrices de Enrique $\mathrm{III}^{40}$, lo integrarían todos los grandes que estuviesen en la corte, quedando abierto a los procuradores de las ciudades y villas del reino ${ }^{41}$. Se satisfacía así parte de las aspiraciones de la nobleza, pues no hay que olvidar que uno de los principios que le inspiraban era «... no consentir nunca el excesivo engrandecimiento de nadie» ${ }^{42}$. El nuevo régimen pretendía legitimarse a través de unas Cortes, que fueron convocadas al efecto, que se reunieron con un formato inusual en Ávila y a las que algunos no tuvieron por tales ${ }^{43}$. En ellas quedó claro que el infante don Enrique y sus parciales no contaban con todo el apoyo ciudadano deseado.

Un medio más para afirmarse en el poder fue el abandono de Tordesillas y el traslado de la corte hacia lugares más seguros -posiblemente camino de Andalucía-, entre otras razones por la agrupación de fuerzas del bando del infante don Juan en la Submeseta norte. Estos lugares fueron, sucesivamente, Ávila y Talavera.

Por otro lado, el control del poder político no podía ser total si al margen quedaba el económico. Esa es la principal razón, no la única, del interés de los sublevados por tener bajo su control el alcázar de Segovia, pues en él se custodiaba el tesoro real ${ }^{44}$.

En esta etapa de afianzamiento se pusieron al descubierto algunos de los fines explícitos o implícitos que perseguían los sublevados. El primero de ellos en el tiempo

cómo los encargados del gobierno del reino trataron de controlarlo, entre otras maneras aumentando el número de consejeros.

${ }^{40}$ El ordenamiento de Enrique III está fechado en Segovia el 15 de septiembre de 1406 y publicado por S. DE Dios, Fuentes para el estudio del Consejo Real de Castilla, Salamanca, 1986, n. ${ }^{\circ}$ v, pp. 21-27.

${ }^{41}$ La fecha de la reforma se conoce por la carta de 22 de julio de 1420 dirigida a Murcia y publicada por J. Abellán Pérez (ed), Documentos..., n. ${ }^{\circ}$ 34, pp. 78-79. Cita el documento M. a Asenjo González, "El poder regio y las ciudades castellanas a mediados del siglo Xv. Pragmáticas, ordenamientos y reuniones de Cortes en el reinado de Juan II", Os Reinos Ibéricos na Idade Media. Livro de Homenagem ao Professor Doutor Humberto Carlos Baquero Moreno, Coordenaçao de Luís Adão da Fonseca, Luís Carlos de Amaral, Maria Fernanda Ferreira Santos, vol. II, Porto, 2003, nota 16, p. 951. Más detalles sobre las razones de la reforma y su intención en J. Hernández díaz, A. Sancho Corbacho y Fco. Collantes de Terán, Colección diplomática..., pp. 48-50. C. Olivera Serrano, "Las Cortes de Castilla en el primer tercio del siglo Xv", Hispania, XLVII (1987), p. 418, pone de manifiesto que no consta que se cumpliera la promesa de dar entrada a los procuradores de las ciudades en el Consejo.

${ }^{42}$ L. SuÁrez Fernández, Nobleza y Monarquía..., p. 89.

${ }^{43}$ Las razones de la convocatoria, los asistentes y las protestas de los procuradores de Burgos los recogen Á. García de Santa María, Crónica ..., pp. 114 y 128-129, y F. Pérez de Guzmán, Crónica ..., pp. 386-387. Este último hecho también se refleja en Cosas sacadas de la Historia del rey Don Juan el Segundo (BL MS Egerton 1875), Edited by A. Mackay y D. Sherman Severin, Exeter, 1981, pp. 12-13. Para E. Benito Ruano, Los infantes de Aragón, Madrid, 1952, p. 24, y para J. Valdeón Baruque, "Las Cortes de Castilla y las luchas políticas del siglo xv (1419-1430)", Anuario de Estudios Medievales, 3 (1966), pp. 293-326, fueron un simulacro. En fechas más reciente J. M. Nieto Soria, "El Auto de Ávila de 1420", Castilla y el mundo feudal. Homenaje al profesor Julio Valdeón, María Isabel del Val Valdivieso y Pascual Martínez Sopena (Dirs.), vol. II, Valladolid, 2009, pp. 679-690, propone la utilización del término «auto» empleado por Fernán Pérez de Guzmán y por Álvar García de Santa María, en contraposición al de «Cortes», y fecha este hecho después del día 4 de agosto y antes del 11 del mismo mes de 1420. Este mismo autor en "La gestación bajomedieval del derecho de resistencia en Castilla: modelos interpretativos", Cahiers d'Études Hispaniques Médiévales, 34 (2011), pp. 19-20, considera el citado «auto» el medio que tuvieron el infante don Enrique y sus partidarios para justificar la acción de Tordesillas, poniéndolo como ejemplo del derecho de resistencia por ruptura de pacto.

${ }^{44}$ La reina habría nombrado tesorero al obispo de Segovia en 1408. A. De Ceballos Escalera y Gila, Alcaides, Tesoreros y Oficiales de los Reales Alcázares de Segovia, Madrid, 1995, p. 146. 
fue el matrimonio del rey, celebrado el domingo 4 de agosto ${ }^{45}$, de cuya demora se culpaba al anterior grupo gobernante. Si el referido matrimonio pudo peligrar creo que lo que no corrió ningún riesgo fue la alianza entre las dos ramas de los Trastamara, sobre todo por los importantes valedores, como don Sancho de Rojas, con que contaba $^{46}$.

Más dificultad existía en la unión entre el infante don Enrique y su prima Catalina, hermana de Juan II. Sin embargo, desde la resistencia más enconada por parte de la infanta -recuérdese su reclusión voluntaria en un monasterio de Tordesillas y las presiones posteriores para que saliera de él- hasta el matrimonio con su primo, el maestre de Santiago, mediaron poco más de tres meses y medio o cuatro ${ }^{47}$. Este matrimonio contaba con la oposición de Fernando Alfonso de Robles ${ }^{48}$, pero, sobre todo, de la reina María de Aragón, hermana del rey de Castilla y de la citada infanta. La reina de Aragón cursó misivas quejándose del desconocimiento que tenía de

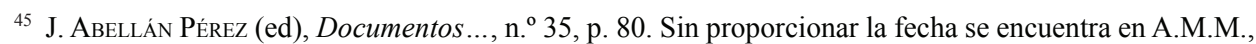
Actas Capitulares (1420 agosto 17), fol. 29r; J. Hernández Díaz, A. Sancho Corbacho y Fco. Collantes de Terán, Colección diplomática..., pp. 48-50; Fco. Collantes de Terán Delorme, Archivo Municipal de Sevilla. Inventario de los papeles del Mayordomazgo del siglo XV, 1417-1430, vol. II, Sevilla, 1980, n. ${ }^{\circ} 39$, p. 77; G. Chacón, Crónica..., p. 39, en L. De BARrientos, Refundición..., p. 36, que es más explícito y da unos breves detalles de las celebraciones que tuvieron lugar, y en J. ZuriTA, Anales de la Corona de Aragón, Edición de Ángel Canellas López, vol. v, Zaragoza, $1980^{2}$, p. 554. Quienes sí ofrecen la fecha son Á. GARCía DE Santa María, Crónica ..., pp. 113-114 y F. Pérez de Guzmán, Crónica ..., p. 384, que contradicen a Barrientos al indicar que aparte de la ceremonia de la boda no hubo ninguna otra fiesta. Estos autores también señalan las posesiones que el rey entregó a su mujer en concepto de arras: fueron las villas de Molina, Atienza, Huete, Deza, Arévalo y Madrigal. Corroborando lo afirmado por los dos cronistas sobre la falta de celebraciones está el documento procedente del A.H.N., Clero. Papeles. Tarragona, leg. 375, n. ${ }^{\circ}$ 141, publicado por Á. L. JAVIERRE Mur, "Relaciones diplomáticas entre Juan II de Castilla y Alfonso V de Aragón. (Documentos para su estudio)", Revista de Archivos, Bibliotecas y Museos, 4 a época, año I, LIII-I (1947), pp. 10-21. El citado matrimonio se festejó en Sevilla con una corrida de toros en La Laguna, como recoge de los Papeles del Mayordomazgo A. Del R. Romero AвAo, "Fiestas de la vida y de la muerte en la Sevilla del siglo Xv", Actas del VI Coloquio Internacional de Historia Medieval de Andalucía. Las ciudades andaluzas (siglos XIII-XVI), Málaga, 1991, p. 294.

46 Don Sancho de Rojas después de los desposorios del rey con la infanta doña María en Medina del Campo se habría dirigido a ella y a su madre, doña Leonor y les habría dado «... a entender cómo él, por bien dellas, más que otro avía tenido manera que este camino se atase». L. DE BARrientos, Refundición..., p. 29. Sin embargo, en su actitud posterior pudo administrar el tiempo en su propio beneficio, tratando de afianzar su poder. Así se deduce de una carta de la reina doña María en la que se contiene una crítica a la actitud del prelado, ya que «... en caso que fuera mucho acuciador en el desposorio del Rey con la Reina, fuera vagaroso en procurar las bodas». Á. García de Santa María, Crónica ..., p. 114. De acuerdo con G. DíEz de Games, El Victorial..., p. 322, el prelado estaría entre los integrantes del equipo de gobierno que habrían aconsejado al monarca que tomase por mujer a la otra infanta menor, su hermana «... a fin de que se tardase el casamiento del rey e a ellos durase más el regimiento».

47 Sin una fecha concreta L. DE BARRIENTOS, Refundición..., p. 36, afirma que el lugar de los desposorios fue Escalona y que el arzobispo de Toledo les desposó, mientras que en la página siguiente indica que la boda tuvo lugar en Talavera. Por razones obvias, creo que se equivoca al hacer intervenir a don Sancho de Rojas en este acto. G. Chacón, Crónica..., p. 41, sitúa el lugar de los desposorios en Talavera. Á. García de SANTA MaríA, Crónica..., p. 136; F. PÉRez de GuZMÁn, Crónica..., pp. 388 y 389, respectivamente, señalan que se celebró en Talavera y que les desposó el arzobispo de Santiago, don Lope de Mendoza, y que fue el día ocho de noviembre. También da cuenta de este matrimonio Á. L. JAVIERRE Mur, "Relaciones diplomáticas...", pp. 29-30.

${ }^{48}$ La reina le encomendó la tutela de sus hijos menores en su testamento, como se puede ver en L. CORELL RuIZ, Una copia del testamento de Catalina de Lancaster, Valencia, 1952, p. 87, y que conocedor de los gustos y sentimientos de la infanta siempre se mostró contrario a este matrimonio, como indica F. PÉREZ DE GUZMÁN, Crónica..., p. 380. 
las intenciones del infante al respecto al propio don Enrique ${ }^{49}$, a su suegra, la reina viuda, doña Leonor ${ }^{50}$, y a importantes e influyentes personajes de la corte castellana en esos momentos como don Álvaro de Luna ${ }^{51}$ y al condestable Dávalos, al que acusa de haber tratado secretamente el matrimonio entre su hermana y el infante y al que exige que la consultara a ella y le escribiera sobre ello ${ }^{52}$. Incluso envió a Castilla a un consejero suyo, micer Gabriel Palomar, doctor en Leyes, para que se informara del estado en que se encontraban los tratos de matrimonio, y solo si era irremediable aceptarlo ${ }^{53}$ pues, como reconocerá con posterioridad a la boda, se le había dicho «... quel matrimonio de los ditos infantes se tractaua contra voluntad de la dita infanta» ${ }^{54}$.

La infanta doña Catalina se nos presenta como una pieza más, ciertamente valiosa, de este importante juego que era el poder en el reino de Castilla. De ser cierto lo que nos ha transmitido García de Santa María, el infante don Enrique no hizo, en este caso, más que seguir el ejemplo que tan excelentes resultados había proporcionado a su padre, utilizar el dinero para comprar voluntades. En efecto, el cronista señala la intervención de Luis de Monsalve y de su madre, Mari Barba, aya de doña Catalina que, aunque alejada, tanta influencia tenía sobre ella ${ }^{55}$.

El matrimonio llevaba implícita la entrega del señorío de Villena, exigencia del infante, y transcurrieron muy pocos días entre el enlace y el día 22 del mismo mes de noviembre cuando Juan II, desde Talavera, entregaba a los recién desposados las villas del marquesado, con título de ducado ${ }^{56}$. Con ello se completaban dos de las más importantes aspiraciones del infante don Enrique: ocuparse del gobierno y casarse con su prima; aunque no todas, porque también quiso tener bajo su poder, en calidad de solariegas, a todas las villas y lugares del Maestrazgo de Santiago.

En paralelo a este proceso de engrandecimiento del infante se produjo otro entre algunos de sus colaboradores y familiares. García Fernández Manrique recibió el

49 A.C.A., Cancillería, reg. 3108, fol. 98v.

50 A.C.A., Cancillería, reg. 3108, fol. 100r.

51 A.C.A., Cancillería, reg. 3108, fol. 99v.

52 A.C.A., Cancillería, reg. 3108, fol. 99r-v.

53 Á. L. Javierre Mur, "Relaciones diplomáticas...”, pp. 27-28.

54 Á. L. Javierre Mur, "Relaciones diplomáticas...”, pp. 29-30.

${ }^{55}$ Le habría dado un lugar a esta señora, y a su hijo ciento cincuenta mil maravedíes anuales de los que el rey había asignado al infante en ese mismo periodo. Á. García de SAnTA María, Crónica..., p. 137.

56 R.A.H., Col. Salazar y Castro, M-39, fols. 48r-51r. Á. García de SAnTa María, Crónica..., p. 137; F. Pérez de Guzmán, Crónica ...., p. 388. La oposición a cumplir el mandato regio la señalan F. PÉrez de GuZMÁn, Crónica ..., p. 400, y J. Zurita, Anales..., p. 569, que indica cómo los de Villena y otras villas rehusaron dar la posesión al infante, alegando que cuando el rey hizo la donación «... no estaba en su libertad». 
condado de Castañeda ${ }^{57}$ y le fue confirmado el de Palenzuela ${ }^{58}$. Pedro Fernández de Velasco, que por su poca edad aún no era del Consejo, pasó a formar parte de él ${ }^{59}$. Rodrigo Alfonso Pimentel recibió la confirmación de las cuarenta lanzas que tenía su padre ${ }^{60}$. Diego Fernández de Quiñones recibió con título vitalicio el alcázar de la ciudad de Oviedo ${ }^{61}$. Y el condestable logró traspasar a su hijo Pedro López Dávalos el cargo de adelantado mayor del reino de Murcia ${ }^{62}$. En estas circunstancias es posible que se entregase a Gome Suárez de Figueroa ${ }^{63}$ la asignación correspondiente al mantenimiento de treinta lanzas.

En uno y otro bando se multiplicaron las donaciones. Entre los que permanecían con el rey el principal beneficiado fue don Álvaro de Luna, al que los sublevados y los del bando del infante don Juan intentaron atraerse ${ }^{64}$. Don Álvaro había recibido recientemente la concesión de la mitad de las penas de las cosas vedadas que se sacasen de Castilla a Portugal y viceversa ${ }^{65}$, y ahora, y de forma correlativa, se le entregaron la villa de Córnago, el 9 de agosto en Ávila ${ }^{66}$; la Huerta del Rey, cerca de Sevilla,

${ }^{57}$ A.D.M.S., leg. 4285, n. ${ }^{\circ}$ 24; R.A.H., Col. Salazar y Castro, M-123, fols. 73v-74v. M. EsCAGEDo SALmón, La Casa de la Vega. Comentarios a las Behetrías Montañesas y el Pleito de los Valles, Estudios de Historia Montañesa II, Torrelavega, 1917, p. 53; L. Cuesta GuTIÉRREZ, Formulario notarial castellano del siglo XV, Madrid, 1948, n. ${ }^{\circ}$ 51, pp. 73-79; E. Martín de Sandoval y C. Travasedo Colón de Carvajal, "Garci Fernández Manrique, I Conde de Castañeda", Altamira, I (1975), pp. 77-78, y R. Pérez Bustamante y GonzÁlez de LA VEGA, Sociedad, Economía, Fiscalidad y Gobierno en las Asturias de Santillana (S. XIII-XV), Santander, 1979, n. ${ }^{\circ}$ XXxix, pp. 379-380. Sobre la concesión de la tenencia del señorío de Castañeda, no sobre la propiedad del condado, véase R. Pérez Bustamante y González de la Vega, "El Condado de Castañeda al tiempo de su concesión por el rey Juan II de Castilla a Garci Fernández Manrique", XL Aniversario del Centro de Estudios Montañeses, vol. I, Santander, 1976, pp. 144-145. R. M. ${ }^{a}$ Montero Tejada, Nobleza y sociedad en Castilla. El linaje Manrique (siglos XIV-XVI), Madrid, 1996, p. 35, llama la atención en el documento de concesión el que no exista ninguna referencia al título de conde, mientras que las crónicas lo mencionan como tal.

58 C. Álvarez Álvarez, Colección documental del archivo de la catedral de León, XII (1351-1474), en Fuentes y Estudios de Historia Leonesa, n. ${ }^{\circ} 60$, León, 1995, n. ${ }^{\circ} 3400$, p. 182. También lo señala, aunque no menciona nada de la confirmación Á. García de Santa María, Crónica ..., p. 137.

59 Á. García de Santa María, Crónica..., p. 95.

${ }^{60}$ V. Á. Álvarez Palenzuela, "Protagonismo político de un linaje portugués en la Castilla de Juan II: Rodrigo Alfonso Pimentel", Os Reinos Ibéricos na Idade Media. Livro de Homenagem ao Professor Doutor Humberto Carlos Baquero Moreno, Coordenação de Luís Adão da Fonseca, Luís Carlos de Amaral, Maria Fernanda Ferreira Santos, vol. III, Porto, 2003, p. 1303, que lo toma de A.H.N., Sección Nobleza. Osuna, leg. 416, n. $^{\circ} 1$.

${ }^{61}$ F. Quiñones de León y de Francisco Martín, Los Merinos Mayores de Asturias y su descendencia. Documentos, vol. II, Madrid, 1925, n. ${ }^{\circ}$ 48, pp. 65-66. C. Álvarez Álvarez, El Condado de Luna en la Baja Edad Media, León, 1982, p. 129, precisa que esta donación se la hizo el rey después de la muerte de su anterior tenedor Diego Menéndez de Valdés.

${ }^{62}$ M. a de los Ll. Martínez CARRILlo, Revolución urbana y autoridad monárquica en Murcia durante la Baja Edad Media (1395-1420), Murcia, 1980, p. 191.

${ }^{63}$ F. Mazo Romero, El Condado de Feria (1394-1505). Contribución al proceso señorializador en Extremadura durante la Baja Edad Media, Badajoz, 1980, p. 154.

${ }^{64}$ G. Chacón, Crónica..., pp. 38 y 40, respectivamente.

${ }^{65}$ R.A.H., Col. Salazar y Castro, M-72, fols. $128 \mathrm{v}-129 \mathrm{r}$.

${ }^{66}$ A.H.N., Sección Nobleza. Osuna, leg. 2189, n. ${ }^{\circ}$ 3; Biblioteca Zabálburu, Sección Miró, carp. M-7, n. ${ }^{\circ}$ 99. M. Diago Hernando, Estructuras de poder en Soria a fines de la Edad Media, Valladolid, 1993, p. 49, da cuenta de la concesión de Córnago y Jubera. 
el 15 del mismo mes, fechada en San Martín de Valdeiglesias ${ }^{67}$; y San Esteban de Gormaz, el 16 de noviembre en Talavera ${ }^{68}$.

El infante don Juan también hizo importantes donaciones a algunos de sus partidarios. Así entregó a Diego Gómez de Sandoval la villa de Maderuelo con su fortaleza y los mil florines y cuatrocientas fanegas de pan que tenía situados en ella ${ }^{69}$. Y concedió al hijo del mariscal Diego Fernández el oficio de alguacil mayor de Córdoba ${ }^{70}$.

\section{LA CAÍDA}

Existieron tres factores que, de una $\mathrm{u}$ otra manera, contribuyeron a acabar con el régimen del infante don Enrique y sus seguidores; estos fueron las discordias dentro del propio grupo gobernante, la oposición armada y la voluntad del rey por liberarse.

\subsection{LAS DIFERENCIAS ENTRE LOS SUBLEVADOS}

El grupo que se hizo con el poder tras los acontecimientos de Tordesillas tenía esencialmente dos elementos de unión ${ }^{71}$ : el primero, era la cabeza de la rebelión, el infante don Enrique; el segundo, su ansia por ejercer el poder, por razones muy variadas, pero entre las que no sería menor la venganza. Si se tiene en cuenta que el gobierno del maestre de Santiago se extiende grosso modo durante cuatro meses y medio, tardaron muy poco en surgir diferencias entre los que le seguían. La principal causa de insatisfacción se debió esencialmente a la formación de un núcleo compuesto por el condestable, el adelantado de León y por García Fernández Manrique, que eran los que prácticamente gobernaban, marginando a los arzobispos de Santiago y de Sevilla, al conde don Fadrique y a los otros caballeros de la coalición. En el caso del conde don Fadrique, que expresó abiertamente su ruptura de la alianza, parece que además

${ }^{67}$ Biblioteca Zabálburu, Sección Miró, carp. M-7, n. ${ }^{0} 100$; R.A.H., Col. Salazar y Castro, 0-20, fol. 149v. La noticia también en J. Loperráez Corvalán, Descripción histórica del Obispado de Osma, con el catálogo de sus prelados, vol. I, Madrid, 1788, pp. 329-332 y en el vol. II, p. 22.

${ }^{68}$ Duquesa de Berwick y Siruela, Catálogo de las colecciones expuestas en las vitrinas del Palacio de Liria, Madrid, 1898, p. XLVIII. Sin proporcionar la fecha lo mencionan Á. García de SANTA María, Crónica ..., p. 137 y F. Pérez de Guzmán, Crónica ..., p. 388. Teniendo en cuenta el documento de archivo, considero erróneo que G. Chacón, Crónica..., p. 48, sitúe esta donación después de la marcha del rey de Talavera y de su liberación en Montalbán, por lo tanto ya en 1421. J. M. CALDERÓN ORTEGA, Álvaro de Luna: riqueza y poder en la Castilla del siglo XV, Madrid, 1998, p. 35, señala que el privilegio de concesión, de 16 de noviembre de 1420 , perdido en la actualidad, no decía nada sobre la dignidad condal de esta concesión como sí lo hace su crónica.

${ }^{69}$ C. J. M. a Ajo GonzÁlez de Rapariegos y Sainz de ZúNíIGA, Inventario General de los Archivos de la Diócesis de Ávila. Fuentes Inéditas para la historia abulense en la Biblioteca de la Real Academia de la Historia, Madrid, 1969.

${ }^{70}$ Biblioteca Zabálburu, Sección Altamira, carp. M-13, n. ${ }^{\circ} 3$.

${ }^{71}$ No sería de carácter menor, como se señalaba antes, caso de Íñigo López de Mendoza, y más tarde en el de la élite gobernante, los vínculos familiares existentes entre algunos de los sublevados, valga entre otros ejemplos el del arcediano de Guadalajara, Gutierre Gómez de Toledo, pariente del ya referido futuro marqués de Santillana y cuñado de Diego Fernández de Quiñones, por el matrimonio de este último con su hermana doña María de Toledo. Sobre esta última cuestión véase W. Merino Rubio, "Dominio de los Quiñones de Luna en León en el siglo xv", Tierras de León, n. ${ }^{\circ}$ 24, año XvI (1976), p. 50. 
pesó el descontento manifiesto del monarca ${ }^{72}$. Esta élite gobernante la integraban personas que tenían vínculos familiares entre sí, por ejemplo García Fernández Manrique era primo del arzobispo de Santiago, don Lope de Mendoza y de Pedro Manrique y, a su vez, consuegro de Ruy López Dávalos por el matrimonio de su hijo Gabriel con Mencía Dávalos. También hay que considerar el ascendiente que tenían ambos Manrique sobre el infante, a los cuales la reina de Castilla acusará de influir en las actuaciones de su hermano ${ }^{73}$.

\subsection{LA OPOSICIÓN ARMADA}

El infante don Juan mostró su desacuerdo con la situación creada. Él y su hermano comienzan una carrera en la que las iniciativas parten del bando del primero ${ }^{74} \mathrm{y}$ a las que se responde por la otra parte. El señor de Lara consideraba que se tenía que «... curar mas por obra que con palabras» y, por lo tanto, su primera reacción fue hacer un llamamiento a todos los caballeros y escuderos que tenían tierras de él para que se juntasen en Peñafiel ${ }^{75}$, comenzando a reunir en torno a sí a los nobles y eclesiásticos contrarios a su hermano. La reacción de don Enrique fue ordenar al rey que hiciese un llamamiento general a todos sus vasallos ${ }^{76}$, a lo que responde su hermano Juan con una misiva a todas las ciudades del reino, informándoles de lo ocurrido en Tordesillas y pidiéndoles que le enviasen sus procuradores ${ }^{77}$. El peligro que entrañaba esta medida lo entrevió claramente el infante don Enrique: un gobierno paralelo podía restar legitimidad al suyo. A pesar de tener en su poder al monarca, la manera de contrarrestarlo era validar el acto de Tordesillas y la forma que consideró más conveniente fue a través de la convocatoria de Cortes.

El proceso de acumulación de fuerzas por cada uno de los dos infantes se realizó de manera bastante rápida. La mayor concentración de tropas se alcanzó en el espacio de un mes, aproximadamente ${ }^{78}$. Las tres mil lanzas del infante don Enrique y las tres mil trescientas del infante don Juan, localizadas en Ávila y en Olmedo ${ }^{79}$, respectivamente, muestran lo equiparadas que estaban las fuerzas de ambos, su gran influencia $^{80}$ y el efecto disuasorio que pretendían conseguir con semejante exhibición de

72 Á. García de Santa María, Crónica ..., pp. 142-143; F. Pérez de Guzmán, Crónica ..., pp. 389-390.

73 A.M.M., Cartulario Real 1411-1429, fol. 106r.

${ }^{74}$ No estoy de acuerdo con la afirmación de J. Vicens Vives, Juan II de Aragón (1398-1479). Monarquía y revolución en la España del siglo XV, Pamplona, 2003, p. 41, cuando señala que el infante don Enrique practicaba la ofensiva, creo, por los hechos que expongo en el texto, que era todo lo contrario.

75 Á. García de Santa María, Crónica ..., pp. 104-105; F. Pérez de Guzmán, Crónica ..., p. 383.

${ }^{76}$ F. Pérez de Guzmán, Crónica ..., pp. 383-384.

77 F. Pérez de Guzmán, Crónica..., p. 384.

${ }^{78} \mathrm{Me}$ baso en los datos que proporciona F. Pérez de GuZMÁn, Crónica ..., p. 385, y en los diferentes documentos que probarían que el rey estuvo en Ávila, prácticamente el mes de agosto.

79 Á. García de Santa María, Crónica ..., p. 119; F. Pérez de Guzmán, Crónica ..., p. 385.

${ }^{80}$ También hay que tener en cuenta que algunas de ellas, sobre todo parte de las que estaban con el infante don Enrique, llegaron convocadas por las misivas regias. En el caso concreto de Gome Suárez, aunque F. Mazo Romero, El Condado..., p. 154, pone al infante don Enrique como emisor de la carta a él dirigida, es posible que fuera encabezada por el nombre del monarca. Lo que ignoro es la razón de su toma de postura por uno de los dos bandos, si era por una mayor afinidad hacia el infante don Enrique debida a la vecindad de sus 
fuerza. La cercanía de las dos poblaciones hacía presagiar lo peor, aunque ignoro las pretensiones últimas de los infantes. Vicens Vives, refiriéndose al infante don Juan, se interroga si pretendía atacar o, simplemente, atemorizar con su despliegue. Según él, su temperamento prudente le haría inclinarse por esta última opción ${ }^{81}$. La actitud que hubiera tomado el infante don Enrique es desconocida. Lo más normal es que hubiera sido defensiva, habida cuenta la fortificación que suponía Ávila ${ }^{82}$ y en que el rey estaba en su poder. En cualquier caso, esto contrastaría con los precedentes y con algunos rasgos de su personalidad.

El enfrentamiento entre los dos infantes hubiera supuesto una nueva guerra en Castilla, de ahí que prácticamente desde los inicios de esta crisis se produjeran intentos de mediación entre ambas partes. Por lo que sabemos, estos tuvieron esencialmente un doble origen ${ }^{83}$; los que llevó a cabo la reina viuda, doña Leonor, en el que se encuadra el de los representantes de los dos infantes; y el de los embajadores de la reina doña María de Aragón. El mayor protagonismo en todo este proceso habría correspondido a doña Leonor, madre de ambos infantes, a cuya intervención Pérez de Guzmán dedica, en mayor o menor medida, cinco capítulos de su crónica ${ }^{84}$. Esta señora es muy muy probable que estuviese auxiliada por su canciller, don Diego de Fuensalida, obispo de Zamora, al menos en lo que sería la última fase de esta crisis, pues parece que desempeñó una importante labor negociadora ${ }^{85}$. La reina se trasladó de Medina del Campo a Madrigal y de esta última población a Ávila, para centrarse finalmente en Fontíveros. Doña Leonor propuso a sus hijos tres soluciones: designar para el Consejo Real a ciertas «... personas buenas e sin sospecha» y que ellos pudiesen estar simultáneamente en la corte; que se turnaran en su presencia al lado del monarca; o bien que se retiraran a sus posesiones, sin poder acudir a la corte salvo en caso de urgente necesidad ${ }^{86}$. Ninguna de ellas era satisfactoria para las dos partes. Si se examinan los meses precedentes, se puede ver que la primera ya se había llevado a cabo y había desembocado en el hecho que se está analizando, por lo tanto en esos momentos hubiera sido inviable. La segunda estaba claro que tampoco, pues al menos el infante don Enrique no quería dar «... lugar a los Infantes sus hermanos que cerca del Rey estuviesen ${ }^{87}$, ni $« \ldots$ al Infante Don Juan ni a ninguno de los de su parcialidad cerca de la persona del Rey ${ }^{88}$. Y la tercera, a pesar de que el infante don Juan la aceptó, es muy probable que lo hiciera por forzar la situación, por saber hasta qué punto estaba dispuesto a ceder su hermano. Es difícil que cualquiera de

señoríos en Extremadura, si era fruto de una convicción personal o de algún tipo de presión. Lo cierto es que en 1421 y tras la liberación del monarca cambió de bando.

${ }^{81}$ J. Vicens Vives, Juan II..., p. 40.

${ }^{82}$ Sobre esta cuestión también llama la atención J. Vicens Vives, Juan II..., p. 40.

${ }^{83}$ Dejo al margen el enfrentamiento real o supuesto que se habría dado en los comienzos de esta crisis entre representantes del condestable, por una parte y del arzobispo de Toledo, por la otra. Se hace difícil aceptar las palabras del cronista, aunque solo sea por situar estos contactos poco después de los hechos de Tordesillas.

Á. García de Santa María, Crónica..., p. 97.

${ }^{84}$ F. Pérez de Guzmán, Crónica ..., pp. 384-385 y 389.

85 Á. García de Santa María, Crónica..., p. 184.

${ }^{86}$ Á. García de Santa María, Crónica..., p. 122, de quién lo toma J. Vicens Vives, Juan II..., p. 41.

${ }^{87}$ F. Pérez de Guzmán, Crónica..., p. 384.

${ }^{88}$ F. Pérez de Guzmán, Crónica..., p. 387. 
estos personajes se hubiera inhibido de los asuntos del reino, en el que tantos intereses tenían o que hubieran renunciado a estar cerca del poder y lo que representaba. $\mathrm{Si}$ encontramos una mayor receptividad por parte del duque de Peñafiel que de su hermano, se debería, entre otras razones a que no tenía nada que perder, sino todo lo contrario, afianzaría su posición. La postura del maestre de Santiago se entiende desde la perspectiva de su posición de poder, de ahí que estuviera temeroso de perder su influencia. Además, es importante destacarlo, hasta esos momentos todo le estaba saliendo bien, ¿por qué no iba a pensar en que pudiera seguir siendo así en un futuro?

No puede hablarse de fracaso total en la mediación de doña Leonor. Bien es cierto que desde un punto de vista político no alcanzó los objetivos perseguidos; sin embargo, sentó las bases de un diálogo entre las dos partes enfrentadas, cuyo fruto fueron las conversaciones de los negociadores de ambos bandos, aunque no lograron ningún acuerdo $^{89}$. Las crónicas, muy personalistas, achacan toda la responsabilidad de estos fracasos al infante don Enrique. Sin duda no se le puede exculpar, pero tampoco al el entorno que le rodeaba, que tenía una gran influencia en sus actos ${ }^{90}$. La intercesión de doña Leonor fue muy positiva desde la perspectiva militar que podía adquirir el enfrentamiento, ya que por su iniciativa se produjo la dispersión de ambos ejércitos ${ }^{91}$. A partir de entonces se iniciaría una nueva fase, la última, en la que, al margen de los asuntos políticos, lo más destacable sería el traslado de la corte fuera del ámbito en el que se movía la monarquía.

En esta nueva etapa se enmarca la mediación de la reina de Aragón. Doña María envió al menos una embajada con el propósito de informarse sobre lo ocurrido en Tordesillas y cuál era la situación del momento en Castilla. Sus representantes se entrevistaron con las dos partes en conflicto, incluidos el rey y la reina, y su suegra, doña Leonor ${ }^{92}$. En el bando de don Enrique los embajadores de la reina de Aragón recibieron una respuesta escueta, sin margen para una posible negociación, en el de don Juan se pusieron a su disposición y culpan al infante don Enrique y a los de su parcialidad de no haber llegado a ningún acuerdo ${ }^{93}$. Doña María estaba muy interesada en la estabilidad de Castilla porque aún no había cobrado la totalidad de la dote y por el posible matrimonio de su hermana, la infanta doña Catalina, con el maestre de Santiago. Aunque carecemos de testimonios posteriores, creo que no hubo más intentos mediadores por su parte.

${ }^{89}$ Los negociadores fueron el almirante Alonso Enríquez, Álvaro de Isorna, obispo de Cuenca, y Alfonso García de Santa María, deán de Santiago y Segovia, por parte del infante don Juan. Los representantes del infante don Enrique, su hermano, fueron Rodrigo de Velasco, obispo de Palencia y el doctor Juan Rodríguez de Salamanca. Á. García de Santa María, Crónica ..., p. 132; F. Pérez de Guzmán, Crónica ..., p. 387.

${ }^{90}$ F. Pérez de Guzmán, Crónica ..., p. 385, lo hace extensivo a quienes rodeaban a ambos infantes «... los Caballeros que estaban así de la una parte como de la otra, esperando procurar sus intereses, no daban a esto lugar, ante por vías exquisitas trabajaban como siempre que la enemistad creciese entre estos señores hermanos, porque ellos acrecentasen sus Estados e consiguiesen lo que deseaban».

91 Á. García de Santa María, Crónica ..., p. 119; F. Pérez de Guzmán, Crónica ..., p. 385.

${ }_{92}$ Los argumentos de esta última para mediar entre sus hijos los recoge F. PÉrEZ de GuzMán, Crónica..., p. 128. E. Benito Ruano, Los Infantes..., p. 24, señala que esos mensajeros apoyarían la gestión de su suegra.

${ }^{93}$ F. Pérez de Guzmán, Crónica..., p. 386. 
El traslado de la corte de Ávila a Talavera se produjo de forma inesperada ${ }^{94}$, y aunque se desconoce el momento exacto, tuvo lugar cuando se derramaron las tropas de los dos grupos, pues de otra manera hubiera sido previsible un agravamiento de la crisis, aunque los sublevados todavía mantuvieron mil lanzas a sueldo del rey. El trayecto elegido no fue el más corto, que era el que pasaba por los puertos de Menga y del Pico y por algunas posesiones del condestable como Colmenar y Arenas, sino otro más oriental que atravesaba San Martín de Valdeiglesias, Torre del Alamín y Escalona. Creo que Talavera, a diferencia de lo que afirma Díez de Games sobre su elección ${ }^{95}$, se concebía como una etapa, ya que el objetivo final sería Andalucía «... porquel Infante tenía en ella muy gran parte ${ }^{96}$, sin olvidar su cercanía a las tierras de la Orden de Santiago ${ }^{97}$, puesto que «... el Infante don Juan e el Arzobispo de Toledo e el Conde don Fadrique e muchos otros caballeros non tenían allá tanta manera como de los puertos arriba tenían ${ }^{98}$. Sin embargo, por razones también ignoradas, la presencia del monarca y de la corte en Talavera se prolongó por espacio de un mes aproximadamente ${ }^{99}$.

\subsection{LOS DESEOS DEL REY POR LIBERARSE}

El tercer factor del fracaso del régimen salido del golpe de Tordesillas fue la voluntad regia por liberarse y, en menor medida, la del grupo opuesto al predominio del infante don Enrique. De acuerdo con las crónicas, se puede diferenciar un doble origen en este último grupo: el de los oficiales de la Casa del rey, depurados por los sublevados, casos de Juan Hurtado de Mendoza y de Fernando Alfonso de Robles como más representativos, que desde muy pronto se pusieron en contacto con el infante don Juan y sus parciales; $y$ el formado alrededor de este infante, que sería quien aglutinara a los que estaban en contra del predominio del maestre de Santiago. Muy poco pudieron hacer salvo presionar de forma esporádica. El rey y los que le rodeaban fueron los verdaderos protagonistas. En efecto, Juan II nunca aceptó de buen grado la situación a la que se vio sometido. En el mismo momento del golpe manifestó su descontento e indignación, después tuvo que aprobar lo hecho y fingir durante meses, aunque en algunas ocasiones su malhumor sería evidente. El rey llegó a odiar y aborrecer al infante por el acto que había cometido contra él, y estuvo en su poder muy a su pesar. En su decisión de liberarse influyeron, sin duda, las misivas que recibía, como la que

94 F. PÉrez de Guzmán, Crónica ..., p. 388. Hay que tener en cuenta también que esta población pertenecía a las posesiones del arzobispo de Toledo. M. ${ }^{a}$ J. SuÁrez Álvarez, La villa de Talavera y su tierra en la Edad Media (1369)-1504), Oviedo, 1982, p. 175. Y también que don Sancho de Rojas estaba enfrentado con el infante don Enrique.

95 «Partió el rey de Ávila, e fue a Talavera, por quanto es lugar más deleytoso de ynbierno para el rey e la reyna». G. DíEz de GAmes, El Victorial..., p. 324.

96 F. Pérez de Guzmán, Crónica ..., p. 389.

97 V. Á. Álvarez Palenzuela, "Enrique...”, p. 48.

98 Á. García de Santa María, Crónica ..., p. 144.

99 El primer documento del que hay constancia está fechado en Talavera el día 28 de octubre. A.D.M.S., leg. 4285, n. $^{\circ}$ 24. La huida del rey de esa población se produjo el día 29 de noviembre, F. PÉREZ DE GUZMÁN, Crónica..., p. 390. 
le envió su hermana, la reina doña María de Aragón, donde le insta a poner gran diligencia en la resolución del problema ${ }^{100}$.

A pesar de todo ello, el personaje que más contribuyó en la liberación del monarca del poder del infante don Enrique fue Álvaro de Luna. Don Álvaro fue el nexo de unión entre los que querían liberar al rey y éste y el instrumento para conocer sus pensamientos. Su presencia constante a su lado, el ascendiente que había logrado y su determinación fueron fundamentales ${ }^{101}$. El papel de don Álvaro en esta cuestión lo han destacado autores como Chacón, para quien fue el artífice del matrimonio entre la infanta doña Catalina y el infante don Enrique, sacrificando la felicidad de la infanta para lograr la liberación de Juan II ${ }^{102}$. Díez de Games y Pérez de Guzmán consideran que fue el que urdió el plan de liberación, el que realizó los contactos políticos y el que se atrajo voluntades ${ }^{103}$. Por su parte, Zurita señala que: «En todas estas altercaciones y movimientos no fue Álvaro de Luna buen medianero con el lugar y privanza que tenía con el rey para poner concordia entre ambos infantes; antes secretamente procuró de desavenir al rey de entreambos» $\rangle^{104}$.

El plan que se gestó en Talavera contó con varios elementos. La prudencia era imprescindible para llevarlo a cabo con éxito, sobre todo si se tiene en cuenta la vigilancia a que estaba sometido el monarca y la presencia del infante a su lado ${ }^{105}$. Don Álvaro tuvo que someter los impulsos juveniles del rey, que pretendió huir en el trayecto de Ávila a Talavera, bajo la observación del peligro a que se exponía ${ }^{106}$. Sin embargo, es interesante la forma en que el rey pretendía hacerlo, «... so color de andar a monte». Llama la atención porque será el método que don Álvaro utilice para lograr su liberación, porque no lo habían empleado antes y porque, una vez en Talavera, lo debieron de utilizar de forma bastante continuada. El secreto también se hacía necesario ${ }^{107}$, por lo que no más de seis o siete personas tuvieron conocimiento de lo que se pensaba hacer, ya que otros se enteraron en el transcurso de la huida ${ }^{108}$. Al corriente de los planes de don Álvaro estaban dos altos nobles que hasta entonces habían sido partidarios del infante don Enrique: el conde don Fadrique de Trastamara y el conde de Benavente, don Rodrigo Alfonso Pimentel. ¿Qué razones les llevaron a abandonar al maestre de Santiago? Del primero conocemos su descontento por la forma de actuar de don Enrique y su círculo más próximo. Es muy posible que se le

100 Á. L. Javierre Mur, "Relaciones diplomáticas...”, pp. 22-24.

101 Su intervención, desde la huida de Talavera hasta la liberación del castillo de Montalbán, la recoge D. T. JAEN, John II of Castile and the grand master Alvaro de Luna. A biography compiled from the chronicles of the reign of king John II of Castile (1405-1454), Madrid, 1978, pp. 41-54.

102 Esta razón tal como se presenta es difícil de admitir. G. CHAcón, Crónica..., p. 40.

103 G. Díez de Games, El Victorial..., p. 325; F. Pérez de Guzmán, Crónica..., p. 389.

104 J. Zurita, Anales..., p. 554.

105 G. Chacón, Crónica..., pp. 40-41. Sobre el último aspecto inserta en la página 41 el siguiente texto. «E porque el infante don Enrique nunca se partía del Rey desde grand mañana que se levantaba, fasta que lo dexaba acostado».

106 F. Pérez de Guzmán, Crónica..., p. 388.

107 Á. García de Santa María, Crónica..., p. 143; F. Pérez de Guzmán, Generaciones, Semblanzas..., p. 715, escribe de Álvaro de Luna que «... era muy discreto, e gran disimulador: fengido e cauteloso, y que mucho se deleytaba usar tales artes y cautelas, ansí que parece que lo habia a natura».

108 F. Pérez de Guzmán, Crónica ..., p. 390. 
hicieran promesas que después se incumplieron. Baste recordar que en su decisión de inclinarse por el bando del infante don Enrique, disfrazado de servicio al rey y de estar con éste, no parece animarle más que el afán de lucro ${ }^{109}$. Don Álvaro sacó provecho de su insatisfacción, lo que se ignora es cómo. Más problemático resulta explicar los motivos que movieron al conde de Benavente a actuar como lo hizo, porque además don Rodrigo Alfonso Pimentel era copero mayor del infante don Enrique ${ }^{110}$. Bien es cierto que su suegro, el almirante don Alfonso Enriquez, militaba en el bando opuesto y que también estaba entre los nobles marginados del grupo de poder. Con todo ello, se carece de datos para indicar con certeza qué le movió a inclinarse por el otro bando. Otro de los elementos favorables que hizo triunfar la huida del rey fue la negligencia, como consecuencia de la rutina. Las dotes psicológicas de don Álvaro se manifiestan claramente en la elección del método. Conocía que la repetición de una misma acción, como era ir de caza, produciría un relajamiento o, en el mejor de los casos, un abandono de la vigilancia que podrían aprovechar para escapar, como así fue ${ }^{111}$.

El momento político en que se produjo la huida del rey era, cuando menos, complejo. En efecto, el infante don Enrique había pedido a los procuradores una gran suma de maravedíes bajo el pretexto de armar un ejército para ir contra Portugal ${ }^{112}$.

El primer aspecto a tratar de la huida es el itinerario seguido por el monarca y sus acompañantes. Se eligió cruzar el río Alberche, afluente del Tajo, que en caso extremo se podía vadear ${ }^{113}$, y que además contaba con un puente en las cercanías de Talavera ${ }^{114}$. Sin duda, se descartó la posibilidad de cruzar el río Tajo, que pasa por la

109 Á. García de Santa María, Crónica ..., p. 112; F. Pérez de Guzmán, Crónica ..., p. 383.

110 A.H.N., Sección Nobleza. Osuna, carp. 56, n. ${ }^{\circ} 10$.

111 «E porque las guardas cabalgaban cadaldía, que eran bien doçientos hombres darmas, tratóse con el Rey que cadaldía saliese a caça dos vezes. E tanto fué el seguir de la caça, que los doçientos hombres que heran de armas tornáronse en çiento, e de çiento en çinquenta, e de çinquenta en non ninguno; tanto que fué a caça el Rey bien çinco o seys días e no fue guarda ninguna con él». Crónica del Halconero de Juan II, Pedro Carrillo de Huete, Edición y estudio de Juan de Mata Carriazo y Arroquia, Madrid, 1946, p. 1. La presencia de doscientos hombres de armas custodiando al rey cada vez que cabalgase se decidió en la aldea de Tuerce Barbas -Villaverde de Medina-, como indica L. DE BARRIENTOS, Refundición ..., p. 36. Este mismo autor expresa la idea de Álvaro de Luna de que el rey cabalgase continuamente y saliese a cazar «... porque pudiese desechar aquella gente de cavallo que continuo salía con él», L. DE BARRIENTOS, Refundición ..., p. 38.

112 Á. García de SAnTA María, Crónica ..., p. 146, introduce el matiz de que el conde don Fadrique alegaba que el reino de Galicia no tenía que pagar, por demorar el otorgamiento; F. PÉrez de Guzmán, Crónica..., p. 390.

113 En el momento de la huida el río no se podía vadear porque «... en este tiempo fizo las mas grandes aguas que se sopiese que ficiera en cincuenta años había». Á. GARCía DE SANTA MARÍA, Crónica..., pp. 147 y 156.

114 Este puente, por su carácter de vía de paso, casi obligatoria, para los ganados trashumantes generaba una importante renta para el concejo talaverano. De él también sabemos que en el momento en que el rey lo atravesó su fábrica era de madera. M. . J. SuÁrez Álvarez, La villa..., pp. 233-234. Además, parte de él estaba en mal estado y al atravesarlo el rey se encontró con el impedimento de una acémila cargada caida en el suelo, lo que dificultó la huida, al ser muy estrecho. Á. García de SANTA María, Crónica ..., p. 147. Sobre este puente véase el artículo de C. PACHECo JimÉnez, “Obras públicas en Talavera de la Reina: los puentes medievales. Aproximación histórica y arqueológica”, Espacio, Tiempo y Forma. Serie III. Historia Medieval, 14 (2001), pp. 175-180, especialmente. 
misma población, que carecía de barcas para atravesarlo ${ }^{115}$ y por el puente ${ }^{116}$. Pero es que, además, pudo deberse a la elección del castillo de Villalba como lugar de acogida, ya que uno de los que huyeron con el rey, Diego López de Ayala, era su señor ${ }^{117}$. El rechazo de Villalba como lugar de refugio revela quizá una sobrevaloración de la fortaleza, pues carecía de buenas defensas. Lo único que queda claro del plan, en estos momentos, es la huida apresurada y el encastillamiento para resistir una posible acometida hasta que llegaran fuerzas para liberarles. A partir de entonces se entra en la fase definitiva y quizá más comprometida de la fuga, con la circunstancia de que ahora sí que se conocen las características del lugar donde se quiere ir. En el trayecto se dejaron los caminos, al menos los más transitados ${ }^{118}$. Se corrió el riesgo del fracaso total al tener que cruzar en barca el río Tajo, que tenía que ir más crecido por las lluvias ${ }^{119}$, y además porque hombres armados de la fortaleza de Malpica salieron a los huidos cuando lo cruzaron ${ }^{120}$. Desde Malpica, en la margen izquierda del río Tajo, hasta el castillo de Montalbán les quedaba por cubrir un trayecto casi idéntico al que habían realizado, de ahí que el rey llegase prácticamente de noche a esa fortaleza ${ }^{121}$. En su elección no se tuvieron en cuenta hechos como a quién pertenecía, puesto que su señora era la reina doña Leonor de Aragón ${ }^{122}$, sino estrictamente estratégicos y su

115 Talavera solo poseía dos barcas, según M. ${ }^{a}$ J. SuÁrez Álvarez, La villa ..., p. 235.

${ }^{116}$ Las referencias al puente que cruzaba el Tajo por Talavera siempre aluden a su mal estado, para lo que se ha dado como razón su mala construcción, siendo necesaria su reparación con mucha frecuencia. F. JIMÉNEZ DE GREGorio, “Tres puentes sobre el Tajo en el Medievo", Hispania, XIv (1954), pp. 167-172, especialmente. También remito a la citada obra de C. PACheCO JiMÉNEZ, "Obras públicas...", pp. 166-175, donde trata sobre el Puente Viejo.

117 Á. García de Santa María, Crónica..., p. 148, da el nombre de Diego López de Toledo y además señala que el rey pensaba quedarse dos días en la fortaleza y que ésta se encontraba a cuatro leguas de Talavera; Crónica del Halconero..., p. 2.

${ }^{118}$ La Crónica del Halconero..., p. 4, señala que «... asomó el Rey por un xaral bien espeso»; mientras que F. Pérez de GuZmán, Crónica ..., p. 391, recoge que «... el camino era asaz aspero».

${ }_{119}$ Para hacer esta afirmación me baso en la Crónica del Halconero..., p. 2, aunque indica que durante la huida «... vieron venir los polvos de la mucha gente que venía de Talavera», también se expresa en los siguientes términos: «E asy pasó la varca, a muy gran peligro, por quanto el ryo de Tajo venía avenido qual nunca bino çinquenta años antepasados». Casi en los mismos términos L. DE BARRIEnTos, Refundición..., p. 39. Á. GARCíA DE SANTA MARÍA, Crónica ..., p. 156, indica que «... en este tiempo fizo las mas grandes aguas que se sopiese que ficiera en cincuenta años había». F. Pérez de GuZMÁn, Crónica ..., p. 390, señala que el día 29 en Talavera «... hacía lodos». Durante estos días de finales de noviembre y principios de diciembre de 1420 el tiempo tuvo que ser lluvioso como ya he señalado y como ocurrió cuando el infante don Juan partió de Olmedo que «... anduvo quanto pudo... por ser las aguas muy grandes». F. Pérez de Guzmán, Crónica ..., p. 396.

${ }^{120}$ L. DE BARRIEnTos, Refundición..., p. 39, pone de relieve que estos caballeros eran del adelantado Diego de Ribera, que era de la parcialidad del infante don Enrique. Á. García de SANTA María, Crónica..., p. 154 y F. Pérez de Guzmán, Crónica ..., p. 391, no señalan este incidente, pero sí que el castillo de Malpica era del adelantado Per Afán de Ribera. Creo que esto debe tomarse en el sentido de un control de los pasos del río por parte de la gente de armas del señor del lugar y no por la del infante don Enrique. Pues, en tal caso, ¿cómo explicar la falta de hombres en el puente sobre el Alberche, por ejemplo?

121 «Y el Rey llegó al castillo quasi a hora de vísperas». F. PéreZ de GuzMÁn, Crónica ..., p. 391.

122 S. DE Moxó y Ortiz de Villajos, Los antiguos señoríos de Toledo. Evolución de las estructuras jurisdiccionales en la comarca toledana desde la Baja Edad Media hasta fines del Antiguo Régimen, Toledo, 1973, p. 139. La donación de Fernando I de Aragón a su mujer está fechada el 21 de marzo de 1416 en Igualada y ha sido publicada por A. Franco Silva, El Señorío toledano de Montalbán. De don Álvaro de Luna a los Pacheco, Cádiz, 1992, n. ${ }^{\circ}$ 1, pp. 97-103, en concreto pp. 98-102. 
cercanía. En efecto, esta fortaleza enclavada en el término municipal de San Martín de Montalbán, se erige sobre un promontorio granítico, situado junto al río Torcón, afluente del Tajo, que discurre por un cortado de cien metros, al que dan sus partes norte y noroeste, y con dos torrenteras al este y al oeste, que lo defienden perfectamente por esos lados. Solo la fachada sur da a un terreno llano donde se concentran todas las defensas. El castillo tiene un perímetro de setecientos metros y un espacio interior de aproximadamente quince mil metros cuadrados ${ }^{123}$, es de planta elíptica y cuenta con cinco torres, de las que dos son pentagonales, más avanzadas, unidas por un arco principal al cuerpo de la fortaleza, que se podía mantener aislada al ser tomada cualquiera de ellas con solo cortar el arco que servía para su unión con la muralla ${ }^{124}$, aunque algunas partes de sus defensas no estarían construidas en $1420^{125}$. En estas circunstancias solo quedaba esperar, y más si se tiene en cuenta que todas las previsiones de ayuda militar -por parte de las Hermandades- y de abastecimiento fallaron ${ }^{126}$.

En el lado del infante don Enrique la evasión del rey causó asombro en un primer momento. Se pasó de intentar alcanzarle a ordenar de forma sosegada lo que se tenía que hacer para aislarle a él y a sus acompañantes. Las medidas que se tomaron fueron esencialmente el control de los pasos del río Tajo y el de las puertas de la ciudad de Toledo, para impedirles su huida, refugio y recibir cualquier ayuda, cercar el castillo

123 J. Porres Martín-Cleto, Castillos de Toledo, Toledo, 1980, p. 18, señala que tiene casi dos hectáreas de superficie.

${ }^{124}$ La descripción está basada en la que hace Á. Dotor, "El castillo de Montalbán”, Boletín de la Asociación Española de Amigos de los Castillos, año v, 17 (1957), p. 134.

125 A. Franco Silva, El Señorío toledano..., p. 14. En esta obra se contiene una excelente colección de fotografías en color del estado actual de la fortaleza con dos planos, pp. 25-56.

${ }^{126}$ El papel que desempeñaron en esta cuestión fue nulo, por las razones que expone F. PÉREZ DE GUZMÁN, Crónica..., p. 393. Por lo tanto, no estoy de acuerdo con A. Álvarez de Morales, Las Hermandades, expresión del movimiento comunitario en España, Valladolid, 1974, p. 82, que afirma que la Hermandad intervendrá decisivamente a favor del monarca durante el cerco a Montalbán. Los que llegaron en ayuda del rey a Montalbán eran miembros de la formada por Toledo, Talavera y Villa Real. El rey a través de su tío, el infante don Fernando, les concedió una especie de reglamento en el que figuran todos los servicios que tenían que prestar y en el que también se recoge la designación de los oficiales de la Hermandad. Como han recogido L. SuÁrez FERnÁndez, "Evolución histórica de las Hermandades castellanas", Cuadernos de Historia de España, XVI (1951), n. ${ }^{\circ}$ 12, pp. 69-70, y J. M. a SÁnchez Benito, Colección de documentos de la Santa Hermandad (13001500), Toledo, 1990, n. ${ }^{\circ} 45$, p. 32. Juan II ratificó los derechos a esa Hermandad el 16 de febrero de 1417 , como consta en: B.N., Mss. 13030, fols. 105r-107r. La confirmación de sus privilegios a la Hermandad de Talavera se encuentra en J. M. ${ }^{a}$ SÁnchez Benito, Colección de documentos..., p. 34, n. ${ }^{\circ}$ 51. L. R. Villegas Díaz, Ciudad Real en la Edad Media. La ciudad y sus hombres (1255-1500), Ciudad Real, 1981, p. 197, considera que la concesión del rango y título de ciudad a Villa Real se lo concedió Juan II por la ayuda que le prestaron durante el asedio al castillo de Montalbán. Sobre las Hermandades y en concreto sobre distintos aspectos de la Vieja, formada por Toledo, Talavera y Villa Real tratan FCO. J. AguAdo SÁnchez, "Las Hermandades. I. Hasta los Reyes Católicos", Revista de Historia Militar, 18 (1965), pp. 47-66, y J. M. a SÁnchez Benito, "Sobre la Hermandad Vieja de Toledo, Talavera y Ciudad Real en la Edad Media. Conflictos jurisdiccionales y poder sobre la tierra", Anuario de Estudios Medievales, 18 (1988), pp. 147-155, y del mismo "Poder y propiedad: los hermanos de la Santa Hermandad Vieja de Toledo, Talavera y Ciudad Real en el siglo Xv", I Congreso de Historia de Castilla-La Mancha. Campesinos y señores en los siglos XIV y XV, vol. vI, Toledo, 1988, pp. 95-100. De carácter general es la obra de J. Puyol y Alonso, Las Hermandades de Castilla y León. Estudio histórico seguido de las ordenanzas de Castronuño hasta ahora inéditas, León, 1982 (Edición facsímil de la publicada en Madrid en 1913). 
de Montalbán y entablar conversaciones con los asediados para lograr su rendición ${ }^{127}$. La primera les falló en parte, al no tener en su poder Puente del Arzobispo ${ }^{128}$, y las dos últimas no tuvieron éxito ${ }^{129}$, lo que unido a la presión que ejercía la llegada del infante don Juan con una numerosa tropa ${ }^{130}$, llevaron al infante don Enrique a levantar el cerco y al rey a recobrar su libertad ${ }^{131}$. Terminaba así el gobierno del maestre de Santiago, caracterizado, entre otros rasgos, por su transitoriedad e inestabilidad.

\section{LAS CONSECUENCIAS}

¿Pero cuáles fueron las consecuencias socio-políticas del asalto al palacio de Tordesillas? En primer lugar la pérdida de crédito y el desprestigio de la monarquía, como acertó a ver claramente la reina doña María de Aragón. En una carta que dirige a su hermano se lamenta de la situación en que Castilla estaba en esos momentos, le advierte sobre los riesgos que se derivarían de la división entre los infantes, le aconseja seguir el ejemplo de su padre y actuar con diligencia, para «... que se pueda spandir e

127 F. Pérez de Guzmán, Crónica ..., pp. 394-395. El infante utilizó los servicios de don Juan de Tordesillas, obispo de Segovia, del condestable, del adelantado Pedro Manrique, de García Fernández Manrique y de los procuradores. Las posibles palabras del obispo de Segovia al rey las recoge D. DE ColmenARES, Historia de la insigne ciudad de Segovia y compendio de las historias de Castilla, Segovia, 1969, pp. 564-565. Sobre el importante papel de los procuradores del reino en este asunto llama la atención J. VALDEÓN BARUQUE, "Las Cortes...", p. 306.

128 Á. García de Santa María, Crónica ..., p. 160; F. Pérez de Guzmán, Crónica ..., p. 392. Por este paso podían llegar las ayudas que esperaban los asediados. El monarca, en carta fechada en 1425 y publicada por Á. L. JAVIERRE Mur, "Relaciones diplomáticas...”, pp. 10-21, manifiesta que «... la qual dicha puente ficieron ellos mucho por la uer a su parte por embargar el pasaje de los sobre dichos, si non que non plogo a Dios que la ouisen e desque esto sopieron se leuantaron de la dicha cerca mas con temor que por su voluntad». El constructor de este puente fue el arzobispo don Pedro Tenorio, como informa R. SÁnchez SeSA, "La actividad constructora de un arzobispo toledano a finales del siglo XIV. Notas sobre articulación y defensa del territorio", Castellum, 2 (1996), p. 72.

129 E. Benito Ruano, Toledo en el siglo XV. Vida política, Madrid, 1961, pp. 14-15, destaca la actuación de Pero López de Ayala, alcalde mayor, aposentador y alcaide del rey, partidario del infante don Enrique, que con su actitud habría impedido al rey refugiarse en la ciudad.

${ }^{130}$ El rey lo señala como motivo para levantar el cerco al que estaba sometido. Á. L. JAVIERRE Mur, "Relaciones diplomáticas...", pp. 10-21. El infante don Juan tuvo que recabar el apoyo de algunas ciudades, como pudo ocurrir en el caso de Burgos. A.G.S., Divs. Castilla, leg. 11, n. ${ }^{\circ} 2$ y A.M.Bu., Sección Histórica, n. ${ }^{\circ}$ 3008. De este último documento dan cuenta J. A. Bonachía Hernando y J. A. Pardos Martínez, Catálogo documental..., n. ${ }^{\circ} 493$, pp. 224-225.

131 La huida del rey inspiró algún poema como el que compuso Villasandino. E. BucETA, "Ensayo de interpretación de la poesía de Villasandino, número 199 del "Cancionero de Baena"”, Revista de Filología Española, XV (1928), p. 356. «Salga el leon que estaua encogido/ en la cueua pobre de la grant 1lanura;/ mire florestas, vergeles, verdura,/ e muestre su gesto muy esclareçido;/ abra su boca e de grant bramido,/ assy que sse espanten quantos oyran/ la bos temerossa del alto Soldan/ e gosesse del trono desque proueydo». Cancionero de Juan Alfonso de Baena, Edición crítica de José María Azáceta, vol. II, Madrid, 1966, n. ${ }^{\circ}$ 199, pp. 361-364. En la Edad Media se recurrió al reino animal en busca de símbolos políticos, el que representaba al rey era el león. J. L. Bermejo CABrero, Máximas, principios..., p. 167. T. F. Ruiz, "Fiestas, torneos y símbolos de la realeza en la Castilla del siglo xv. Las fiestas de Valladolid de 1428", Realidad e imágenes del poder. España a fines de la Edad Media, (Adeline Rucquoi, coord.), Valladolid, 1988, p. 259, matiza que en la Edad Media el león domado representa el fracaso y habla de un león libre, suelto de su cautiverio, Juan II, y de un león domado, su primo el infante don Enrique. 
dizir por todo el mundo que en las primicias de vuestra jouentut haues sauido extirpar tal division de vuestros regnos e regir e gouernar aquellos en buan paç e en stamiento reposado », ya que por el contrario los «... homicidios, robos, sacrilegios, incendios, raptos e otros males que se pueden seguir de la diuision sobredita seran imputados a vos... de guisa que extirpada de vuestros Regnos e tierras toda diuision sean conseruados... a seruiçio de Dios e exalçamiento de vuestra corona» ${ }^{132}$. El mismo monarca se lo recordará más tarde a los procuradores del reino llegados a Montalbán, cuando se refiera a lo ocurrido en Tordesillas diciéndoles que «... le habian mucho ofendido, e habian prendido algunos de los suyos, e otros habian echado de la Corte, e se habian apoderado de su persona e de su casa e Reynos en gran deservicio suyo e injuria de su prehemiencia real ${ }^{133}$. Esa misma impresión tuvo don Álvaro de Luna, para el que una situación como la que estaba viviendo el rey era «... dar grand mengua a su corona e estado real, e grand escándalo a sus reynos» ${ }^{134}$.

En el mismo plano, se puede afirmar que, durante todo el tiempo que duró la cautividad del rey, el infante don Enrique, que pretendía un control hegemónico del poder, ejerció un férreo control de las personas que visitaban al monarca, y tanto a él como a la reina se les obligó a seguir sus designios, si bien su hermana parece que lo aceptó de buen grado ${ }^{135}$. El maestre de Santiago no deseaba que sus hermanos estuviesen cerca del rey, ni tampoco alguno que fuese de su parcialidad. Durante su gobierno se militarizó la corte, hasta extremos entonces desconocidos, al acordar tener mil lanzas de continuo a sueldo del rey ${ }^{136}$, lo que demuestra una gran inseguridad y enormes deseos por reforzar su poder y preservarlo ${ }^{137}$.

Desde un punto de vista institucional, el mandato del infante don Enrique supondrá la «... pérdida de vitalidad» de las Cortes ${ }^{138}$, sobre todo por su manipulación. Pero la convocatoria de Cortes también puso al descubierto otro problema, la escisión de las ciudades de Castilla, entre partidarias y enemigas del infante. A pesar de alguna medida que puede calificarse como aperturista, como la representación ciudadana en el Consejo Real, la etapa de gobierno del infante don Enrique respondería a un criterio conservador. En efecto, según González Alonso, el esquema de funcionamiento es el mismo que el de otras sublevaciones nobiliarias del cuatrocientos castellano,

${ }^{132}$ Publicada por Á. L. JaVIERRE Mur, "Relaciones diplomáticas...”, pp. 22-24. Creo que, al margen de esto, la reina de Aragón también envió una embajada al rey don Juan. F. PÉrez de Guzmán, Crónica ..., p. 386. Sobre el concepto de corona, desde un punto de vista político es interesante J. M. NiETo Soria, Fundamentos ideológicos..., p. 227.

133 F. Pérez de Guzmán, Crónica ..., p. 395. Sobre la preemimencia real veáse J. M. Nieto Soria, Fundamentos ideológicos..., p. 243. Este concepto, tal como se formula, puede asimilarse a la idea de soberanía, en el sentido de que el rey posee la más alta jurisdicción del reino y ninguna otra instancia puede comparársele, sobre lo cual trata el artículo de J. L. Bermejo CABrero, "Orígenes medievales en la idea de soberanía”, Revista de Estudios Políticos, 200-201 (1975), pp. 283-290.

134 G. Chacón, Crónica..., p. 39.

135 V. Á. Álvarez Palenzuela, "María, infanta de Aragón y reina de Castilla", Estudos em Homenagem ao Professor Doutor José Marques, vol. IV, Porto, 2006, pp. 349-370, en concreto en la p. 352.

136 Á. García de Santa María, Crónica ..., p. 309; F. Pérez de Guzmán, Crónica ..., p. 385.

$137 \mathrm{Su}$ modo de proceder se ajusta a lo que señala J. HeErs, Les partis et la vie politique dans l'Occident médiéval, Paris, 1981, p. 41, cuando afirma que «... se trata de tomar y de conservar la totalidad del poder excluyendo completamente a otras fuerzas políticas». La traducción es mía.

138 J. Valdeón Baruque, “Las Cortes...”, pp. 302-306. 
tendentes a conservar y consolidar los intereses de los grupos privilegiados, en contraposición a lo que él considera componentes modernos y renovadores de la política monárquica ${ }^{139}$.

La complicada situación política provocó la división entre los grupos rectores de la sociedad de la época. La reina de Aragón, cuando señala la gran potencia que los infantes tenían, advierte a su hermano que los nobles, a los que no cita expresamente, se dividirían, con los problemas que ello ocasionaría al reino ${ }^{140}$. En efecto, linajes de la alta nobleza como los Mendoza, agraviados por lo que se les había hecho a algunos de sus miembros, se inclinaron mayoritariamente hacia el infante don Juan ${ }^{141}$. El almirante Enríquez contaba con tres de sus yernos militando en bandos diferentes. Por un lado, Juan Hurtado de Mendoza, marido de su hija Inés y uno de los defenestrados en Tordesillas, en el de don Juan, y en el del infante don Enrique los maridos de sus hijas Leonor y Constanza, Rodrigo Alfonso Pimentel y Juan de Tovar, respectivamente. Y para ahondar más en la división, algunos linajes de ámbito regional, que tenían gran influencia en el gobierno de las ciudades, también se declararon favorables por uno de los infantes. Así ocurrió en Toledo donde buena parte de los linajes de la nobleza -Ayala, Tenorio y Carrillo- se inclinaron por don Enrique ${ }^{142}$. En Sevilla, con la excepción de Pedro de Stúñiga, todos los miembros de la alta nobleza, como don Enrique de Guzmán, conde de Niebla, don Pedro Ponce de León, señor de Marchena, además del adelantado mayor de Andalucía y de don Diego de Anaya, arzobispo de la ciudad, eran partidarios del infante don Enrique ${ }^{143}$. Los que se declararon neutrales fueron requeridos por uno y otro infante y, en algún caso como los de Pedro de Stúñiga y el

139 B. González Alonso, Sobre el Estado y la Administración de la Corona de Castilla en el Antiguo Régimen. Las Comunidades de Castilla y otros estudios, Madrid, 1981, p. 12.

140 Á. L. JaVierre Mur, "Relaciones diplomáticas...”, pp. 22-24.

141 Según Fco. Layna Serrano, Historia de Guadalajara y sus Mendozas en los siglos XV y XVI, Guadalajara, $1993^{2}$, p. 166, no fue así en el caso de Íñigo López de Mendoza, señor de Hita y de Buitrago y futuro marqués de Santillana quien, influido por su pariente y protector don Gutierre Gómez de Toledo, se inclinó por el bando del maestre de Santiago. Además, H. NAder, Los Mendoza y el Renacimiento español, Guadalajara, 1986, p. 69, señala que el arcediano de Guadalajara llevó a participar en esta acción al futuro marqués de Santillana, en alianza con sus primos Fernán Pérez de Guzmán, Fernán Álvarez de Toledo y Pedro Fernández de Velasco. En el mismo sentido se pronuncia A. B. SÁnchez Prieto, La Casa del Infantado (1350-1531). Relaciones politicas, poder social y organización del linaje, Tesis doctoral inédita, Universidad Complutense, vol. I, Madrid, 1994, p. 60, que añade el hecho de que Juan Hurtado de Mendoza era tío de Íñigo y además había sido su tutor. Su presencia en Talavera consta en F. PÉREZ dE GuzMÁn, Crónica ..., p. 391. Señalo la coincidencia de que Íñigo López de Mendoza milite en el mismo bando que su cuñado, García Fernández Manrique y el primo de éste, Pedro Manrique, anteriormente enfrentados, que además era primo del futuro marqués de Santillana. Si este último influyó en la decisión que tomó al respecto el señor de Hita y de Buitrago lo desconzco. Lo cierto, además de su filiación, es que había sido tutor de su mujer, doña Catalina Suárez de Figueroa, y en quien Íñigo hizo pleito homenaje de consumar su matrimonio.

142 A. Franco Silva, El Condado de Fuensalida en la Baja Edad Media, Cádiz, 1994, p. 57. Hay que destacar que el segundo de ellos, Alfonso Tenorio de Silva, adelantado mayor de Cazorla se convirtió en tránsfuga, pues casi desde los comienzos estaba entre los partidarios del infante don Juan, formando parte incluso de una embajada al monarca, y a partir de este momento y de su estancia en la corte se inclinó por el infante don Enrique, tomando parte en las Cortes de 1420 y en la persecución del monarca tras su huida de Talavera. F. PÉREZ dE Guzmán, Crónica ..., pp. 384, 387 y 391, respectivamente. Llamo la atención sobre la circunstancia de que el arzobispo de Toledo, de quien dependía su cargo, milite en un bando y el adelantado de Cazorla en otro.

143 R. SÁnchez Saus, Caballería y linaje en la Sevilla medieval. Estudio genealógico y social, Cádiz, 1989 , p. 441. 
del conde don Fadrique, encontraron ocasión propicia para cobrar deudas impagadas e incrementar su estado ${ }^{144}$. También se produjo la división de la nobleza en Murcia ${ }^{145}$ que, a la postre, logró sacudirse el gobierno del condestable ${ }^{146}$. Las órdenes militares también se dividieron. Así, la de Alcántara estuvo al lado del infante don Juan ${ }^{147}$ y la de Calatrava al del infante don Enrique ${ }^{148}$, además de la de Santiago.

El golpe incluso habría tenido consecuencias de índole fiscal, como conocemos por Murcia, donde provocó «... un giro revisionista a la recaudación de las ocho monedas últimas de $1420 \gg^{149}$.

Respecto a la política exterior, el gobierno del infante don Enrique puso en peligro el acuerdo logrado con Portugal en 1411 e invalidó las promesas hechas a sus embajadores un día antes de los sucesos de Tordesillas ${ }^{150}$. De las tres posturas existentes: concesión de una paz perpetua, tregua por breve tiempo o hacer una armada y apercibir a la gente de guerra, acabó triunfando la última, si bien el elevado coste de la operación la hizo inviable ${ }^{151}$. En cualquier caso, el desaire a los embajadores portugueses motivó que se tomasen medidas preventivas en la Tierra de Sevilla ${ }^{152}$ y que se retrasase la firma de un tratado de paz definitivo hasta 1423.

Otra consecuencia de su gobierno en las relaciones exteriores fue la demora en el envío de la flota que se armaba en Santander y que se mandaba en auxilio del rey de

144 Á. García de Santa María, Crónica ..., p. 112; F. Pérez de Guzmán, Crónica ..., p. 383.

145 Por ejemplo, dentro del propio linaje Fajardo se encuentra a Diego Fajardo en el bando del infante don Juan y a Alfonso Yáñez Fajardo en el del infante don Enrique. J. Torres FonTes, "Un libro peligroso", LibroHomenaje a Antonio Pérez Gómez, vol. II, Cieza, 1978, p. 249.

146 M. a De los Ll. Martínez CARrillo, Revolución urbana ..., pp. 190-192.

147 En el caso del maestre de Alcántara, don Juan de Sotomayor, se puso desde muy pronto al servicio del infante don Juan, como señalan F. PÉrez de Guzmán, Crónica..., p. 383 y A. Torres y TAPIA, Crónica de la Orden de Alcántara, t. II, Mérida-Trujillo-Alcántara, 1999, p. 244 (Edición facsímil de la editio princeps de 1763). Torres y Tapia corrige a FCO. DE RADES y ANDRADA, Crónica de las tres Órdenes de Santiago, Calatrava y Alcántara, Barcelona, 1980, fol. 36v (Facsímil de la publicada en Toledo, 1572), que escribe que el maestre de la Orden de Alcántara fue partidario del infante don Enrique porque al ser maestre de Santiago le podía hacer mucho daño al tener su orden buena parte de las posesiones en Extremadura.

148 F. Pérez de Guzmán, Crónica ..., p. 383. No queda clara la adscripción de don Luis de Guzmán en FCo. DE RADES y ANDRADA, Crónica ..., fol. 68v, donde dice que siempre estuvo al servicio del rey, con su persona y con los caballeros de su orden. Lo que se deduce de la lectura de F. PÉrez de Guzmán, Crónica..., p. 396, es que en la fase final del gobierno del infante don Enrique se debió de pasar al otro bando, pues el rey le encomienda acompañar a la reina hasta Toledo. Poco después estaba en el consejo que el monarca convocó, como se contiene en Á. García de Santa María, Crónica ..., p. 137 y en F. Pérez de Guzmán, Crónica ..., p. 399.

149 M. a De los Ll. Martínez CARrillo, ““Servicios” castellanos y política municipal (1420-1450)”, Miscelánea Medieval Murciana, XIV (1987-1988), p. 308.

${ }^{150}$ Según toma de una carta del rey de Castilla al abad de Poblet en julio de 1425, procedente del A.H.N., Clero. Papeles. Tarragona, leg. 375, n. ${ }^{\circ} 141$ y publicada por Á. L. JAVIERRE Mur, "Relaciones diplomáticas...", pp. 10-21, «... vn día antes del dicho insulto se había concordado la pas en cierta forma con los embaxadores del dicho rey de Portogal».

151 Las fuentes consultadas discrepan a la hora de evaluar el coste de la operación de armar una flota y disponer de ocho mil lanzas y treinta mil peones. Á. García de SANTA María, Crónica ..., p. 139 y F. PÉREZ dE GuZmán, Crónica..., pp. 388-389, la estiman en ciento veinte millones de maravedíes, mientras que según se expresa Juan II en carta al abad de Poblet, publicada por Á. L. JAVIERRE Mur, "Relaciones diplomáticas...", pp. 10-21, serían «setenta cuentos».

152 Fco. Collantes de Terán Delorme, Archivo Municipal..., vol. iI, n. ${ }^{\circ}$ 68-i y it, p. 82. 
Francia ${ }^{153}$. También se intentó establecer un contacto directo con la Santa Sede, que tenía como principales objetivos dar a conocer a Martín V lo ocurrido en Castilla y las razones que habían provocado el levantamiento, además de obtener del pontífice el beneplácito, para que las villas y lugares que pertenecían al Maestrazgo de Santiago pasasen al infante don Enrique y a sus sucesores. Para ello se dispuso enviar al arcediano de Guadalajara ${ }^{154}$, que debería salir desde Sevilla y embarcar en Cádiz, provisto de una importante suma de dinero, diez mil doblas de oro, de la Hacienda regia «... para dar en la Corte Romana, donde le paresciese que complia» ${ }^{155}$. Sin embargo, la embajada no cumplió todos los objetivos previstos, sobre todo por los cambios que tuvieron lugar en Castilla a finales de 1420, y se vio superada por otra que envió el monarca castellano a Martín V, al frente de la cual iba don Álvaro de Isorna, obispo de Cuenca ${ }^{156}$. Por la parte del pontífice sí que se produjeron movimientos, pues el papa encomendó a su legado, Pedro de Fonseca, cardenal de Santángelo, el logro de la paz en Castilla, inclinándose a favor de Juan II ${ }^{157}$. Sin duda, Martín V, aunque solo atendiera a razones religiosas, no quería una división de la jerarquía eclesiástica española entre distintos bandos políticos, que venía a prolongar la que había tenido lugar años atrás en la Cristiandad durante el Cisma.

\section{CONCLUSIONES}

Las conclusiones podemos resumirlas en varios puntos:

- El «golpe» de Tordesillas fue una pugna más de la lucha que mantuvieron la monarquía y la nobleza castellanas en el siglo xv.

- La forma de acceso al poder por parte del infante don Enrique y sus partidarios supuso un desprestigio para la monarquía y algunas instituciones de gobierno.

- Los nobles, de uno y otro bando, salieron reforzados al lograr importantes concesiones.

- Supuso la división de los grupos rectores de la sociedad y de las ciudades.

- Puso en riesgo alianzas estratégicas y acuerdos internacionales.

- Sirvió para aupar al poder a un hombre nuevo, don Álvaro de Luna.

153 F. Pérez de Guzmán, Crónica ..., p. 389. M. de Castro y Castro, El Real Monasterio de Santa Clara de Palencia y los Enríquez, Almirantes de Castilla, Valladolid, 1982, p. 64, señala este retraso.

154 V. Beltrán de Heredia O.P., Cartulario de la Universidad de Salamanca (1218-1600), vol. I, Salamanca, 1970, p. 304, destaca que en esos momentos se estaba tramitando en Roma el proceso abierto sobre los encuentros que hubo entre el bando de don Gutierre y el del depuesto obispo de Plasencia, don Gonzalo de Stúñiga, por lo que a don Gutierre le interesaba encontrarse en Roma para defenderse.

155 Á. García de SAnta María, Crónica..., pp. 134-135, menciona razones públicas y razones secretas. F. Pérez de Guzmán, Crónica..., p. 388. La actuación del arcediano de Guadalajara, don Gutierre Álvarez de Toledo, en esta embajada la señala J. M. NiETo Soria, Un crimen en la corte. Caída y ascenso de Gutierre Álvarez de Toledo, Señor de Alba (1376-1446), Madrid, 2006, pp. 184-187.

156 F. Pérez de Guzmán, Crónica ..., p. 403. V. Beltrán de Heredia O.P., Cartulario..., vol. i, p. 273, señala que entre los asuntos que se le encomendaron estaban la presentación del rótulo de gracias expectativas para el personal de capellanes, servidores y dilectos del monarca, y sobre todo la negociación de la bula de cruzada y las tercias de fábrica, de forma permanente, para luchar contra los musulmanes. Los principales rasgos biográficos de Isorna, durante su etapa como obispo de Cuenca, los ha resumido J. DíAz IBÁñEz, Iglesia, sociedad y poder en Castilla. El obispado de Cuenca en la Edad Media (siglos XII- XV), Cuenca, 2003, pp. 111-114.

157 L. SuÁrez Fernández, Castilla, el Cisma y la Crisis Conciliar (1378-1440), Madrid, 1960, p. 106. 